\title{
Email for clinical communication between healthcare professionals (Review)
}

\author{
Pappas Y, Atherton H, Sawmynaden P, Car J
}

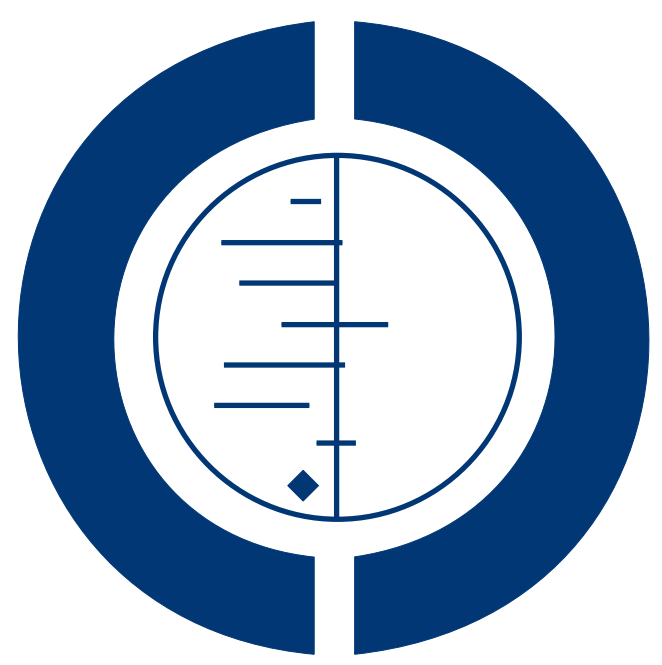

\section{THE COCHRANE COLLABORATION $^{\circledR}$}

This is a reprint of a Cochrane review, prepared and maintained by The Cochrane Collaboration and published in The Cochrane Library 2012, Issue 9

http://www.thecochranelibrary.com

\section{WILEY}

Email for clinical communication between healthcare professionals (Review)

Copyright $\odot 2012$ The Cochrane Collaboration. Published by John Wiley \& Sons, Ltd. 
TABLE OF CONTENTS

HEADER . . . . . . . . . . . . . . . . . . . . . . . . . . . . . . . . . . . . . . . 1

ABSTRACT . . . . . . . . . . . . . . . . . . . . . . . . . . . . . . . . . . . . . . . . 1

PLAIN LANGUAGE SUMMARY . . . . . . . . . . . . . . . . . . . . . . . . . . . . . . . . . . .

BACKGROUND . . . . . . . . . . . . . . . . . . . . . . . . . . . . . . . . . . . . . .

OBJECTIVES . . . . . . . . . . . . . . . . . . . . . . . . . . . . . . . . . . . . . . . . . . . .

METHODS . . . . . . . . . . . . . . . . . . . . . . . . . . . . . . . . . . . . . . .

RESULTS . . . . . . . . . . . . . . . . . . . . . . . . . . . . . . . . . . . . . . . 8

Figure 1. . . . . . . . . . . . . . . . . . . . . . . . . . . . . . . . . . . . . . 99

Figure 2. . . . . . . . . . . . . . . . . . . . . . . . . . . . . . . . . . . . . . . . . . . 11

DISCUSSION . . . . . . . . . . . . . . . . . . . . . . . . . . . . . . . . . . . . . . . . . . . . . .

AUTHORS' CONCLUSIONS . . . . . . . . . . . . . . . . . . . . . . . . . . . . . . . . . . . .

ACKNOWLEDGEMENTS . . . . . . . . . . . . . . . . . . . . . . . . . . . . . . . . . . . . . . . 14

REFERENCES . . . . . . . . . . . . . . . . . . . . . . . . . . . . . . . . . . . . . . . . 15

CHARACTERISTICS OF STUDIES . . . . . . . . . . . . . . . . . . . . . . . . . . . . . . 18

DATA AND ANALYSES . . . . . . . . . . . . . . . . . . . . . . . . . . . . . . . . . . . 23

Analysis 1.1. Comparison 1 Email reminder compared to usual care - Primary outcome: professional actions or performance,

Outcome 1 Patient rec'd bone mineral density measurement. . . . . . . . . . . . . . . . . . . . . 23

Analysis 1.2. Comparison 1 Email reminder compared to usual care - Primary outcome: professional actions or performance,

Outcome 2 Patient rec'd BMD measurement or medication. . . . . . . . . . . . . . . . . . . . . . . . . . 24

Analysis 1.3. Comparison 1 Email reminder compared to usual care - Primary outcome: professional actions or performance,

Outcome 3 Patient received medication only. . . . . . . . . . . . . . . . . . . . . . . . . . . . . $\quad 25$

Analysis 1.4. Comparison 1 Email reminder compared to usual care - Primary outcome: professional actions or performance,

Outcome 4 Patient received neither BMD measurement nor medication. . . . . . . . . . . . . . 25

APPENDICES . . . . . . . . . . . . . . . . . . . . . . . . . . . . . . . . . . . . . 26

HISTORY . . . . . . . . . . . . . . . . . . . . . . . . . . . . . . . . . . . . . . . 32

CONTRIBUTIONS OF AUTHORS . . . . . . . . . . . . . . . . . . . . . . . . . . . . . . . . . . . . . . . . . . . .

DECLARATIONS OF INTEREST . . . . . . . . . . . . . . . . . . . . . . . . . . . . . . . . . . . .

SOURCES OF SUPPORT . . . . . . . . . . . . . . . . . . . . . . . . . . . . . . . . . . . . . . . . . . . . . .

DIFFERENCES BETWEEN PROTOCOL AND REVIEW . . . . . . . . . . . . . . . . . . . . . . . . . 33

INDEX TERMS . . . . . . . . . . . . . . . . . . . . . . . . . . . . . . . . . . . . 34 


\title{
[Intervention Review] \\ Email for clinical communication between healthcare professionals
}

\author{
Yannis Pappas ${ }^{1}$, Helen Atherton ${ }^{2}$, Prescilla Sawmynaden ${ }^{3}$, Josip Car $^{4,5}$ \\ ${ }^{1}$ School of Health Sciences, City University London, London, UK. ${ }^{2}$ Department of Primary Care Health Sciences, Oxford University, \\ Oxford, UK. ${ }^{3}$ Department of Primary Care and Public Health, Imperial College London, London, UK. ${ }^{4}$ Global eHealth Unit, \\ Department of Primary Care and Public Health, School of Public Health, Imperial College London, London, UK. ${ }^{5}$ Department of \\ Family Medicine, Faculty of Medicine, University of Ljubljana, Ljubljana, Slovenia \\ Contact address: Yannis Pappas, School of Health Sciences, City University London, Northampton Square, London, EC1V 0HB, UK. \\ Yannis.pappas.1@city.ac.uk. \\ Editorial group: Cochrane Consumers and Communication Group. \\ Publication status and date: New, published in Issue 9, 2012. \\ Review content assessed as up-to-date: 5 January 2010. \\ Citation: Pappas Y, Atherton H, Sawmynaden P, Car J. Email for clinical communication between healthcare professionals. Cochrane \\ Database of Systematic Reviews 2012, Issue 9. Art. No.: CD007979. DOI: 10.1002/14651858.CD007979.pub2. \\ Copyright (C) 2012 The Cochrane Collaboration. Published by John Wiley \& Sons, Ltd.
}

\begin{abstract}
A B S T R A C T
Background

Email is a popular and commonly-used method of communication, but its use in healthcare is not routine. Where email communication has been utilised in health care, its purposes have included use for clinical communication between healthcare professionals, but the effects of using email in this way are not known. This review assesses the use of email for two-way clinical communication between healthcare professionals.
\end{abstract}

\section{Objectives}

To assess the effects of healthcare professionals using email to communicate clinical information, on healthcare professional outcomes, patient outcomes, health service performance, and service efficiency and acceptability, when compared to other forms of communicating clinical information.

\section{Search methods}

We searched: the Cochrane Consumers and Communication Review Group Specialised Register, Cochrane Central Register of Controlled Trials (CENTRAL, The Cochrane Library, Issue 1 2010), MEDLINE (OvidSP) (1950 to January 2010), EMBASE (OvidSP) (1980 to January 2010), PsycINFO (1967 to January 2010), CINAHL (EbscoHOST) (1982 to February 2010), and ERIC (CSA) (1965 to January 2010). We searched grey literature: theses/dissertation repositories, trials registers and Google Scholar (searched July 2010). We used additional search methods: examining reference lists, contacting authors.

\section{Selection criteria}

Randomised controlled trials, quasi-randomised trials, controlled before and after studies and interrupted time series studies examining interventions in which healthcare professionals used email for communicating clinical information, and that took the form of 1) unsecured email 2) secure email or 3) web messaging. All healthcare professionals, patients and caregivers in all settings were considered.

\section{Data collection and analysis}

Two authors independently assessed studies for inclusion, assessed the included studies' risk of bias, and extracted data. We contacted study authors for additional information. We report all measures as per the study report.

Email for clinical communication between healthcare professionals (Review)

Copyright @ 2012 The Cochrane Collaboration. Published by John Wiley \& Sons, Ltd. 


\section{Main results}

We included one randomised controlled trial involving 327 patients and 159 healthcare providers at baseline. It compared an email to physicians containing patient-specific osteoporosis risk information and guidelines for evaluation and treatment with usual care (no email). This study was at high risk of bias for the allocation concealment and blinding domains. The email reminder changed health professional actions significantly, with professionals more likely to provide guideline-recommended osteoporosis treatment (bone density measurement and/or osteoporosis medication) when compared with usual care. The evidence for its impact on patient behaviours/ actions was inconclusive. One measure found that the electronic medical reminder message impacted patient behaviour positively: patients had a higher calcium intake, and two found no difference between the two groups. The study did not assess primary health service outcomes or harms.

\section{Authors' conclusions}

As only one study was identified for inclusion, the results are inadequate to inform clinical practice in regard to the use of email for clinical communication between healthcare professionals. Future research needs to use high-quality study designs that take advantage of the most recent developments in information technology, with consideration of the complexity of email as an intervention, and costs.

\section{PLAIN LANGUAGE SUMMARY}

\section{Using email for healthcare professionals to contact each other}

Email is now a popular method of communication but it is not so commonly used in health care. There has been no definitive review of the research evidence to see how healthcare professionals using email to contact each other might work. This review attempted to investigate how patients, healthcare professionals and health services may be affected by it and how it might fit into health systems.

We found that there was not much evidence for how health professionals use email to communicate, as we found only one trial. This trial included 327 patients and 159 healthcare providers, and compared an email reminder for physicians with usual care. It found that healthcare professionals in receipt of an email reminder were more likely to provide guideline-recommended osteoporosis treatment than those who did not receive a reminder, and this may or may not have improved patient care. We were unable to properly assess its impact on patient behaviours/actions as the results were mixed. The study did not measure how email affects health services, or whether email can cause harms.

As there is a lack of evidence for the effects of healthcare professionals using email to communicate with each other, we recommend that high-quality research is carried out to evaluate the use of email for this purpose. Future research should look at the costs of using email and take into account ongoing changes in technology.

\section{B A C K G R O U N D}

\section{Related systematic reviews}

This review forms part of a suite of reviews, incorporating four other reviews:

- email for the provision of information on disease prevention and health promotion (Atherton 2009a);

- email for clinical communication between patients/ caregivers and healthcare professionals (Atherton 2009c);
- email for communicating results of diagnostic medical investigations to patients (Meyer 2012); and

- email for management of healthcare appointments and attendance reminders (Atherton 2012 in press).

\section{The use of email}

The use of email as a medium for business and social communication is increasingly common (Pew 2005). This is consistent with the global expansion of users on the Internet, with $90 \%$ of Internet users said to use email (Pew 2005; IWS 2007). While 
industries such as insurance and banking have readily embraced such new technology in order to compete on the global stage (CBI 2006), the healthcare sector has been more cautious in accepting it (Neville 2004). The vast majority of literature on the use of email originates in North America and it is uncertain whether the results of such research will be applicable to other international healthcare environments, where email availability and technology can be very different.

\section{Email for clinical communication between healthcare professionals}

Healthcare professionals have been communicating via email since the early 1990s, for varying purposes such as consulting with colleagues and scheduling meetings (Moyer 1999). Communication between healthcare professionals can occur on several different levels; from one-on-one communication to that between members of a multidisciplinary team, and official communication such as that between healthcare professionals and organisations. A survey of over 4000 US physicians showed that in $200663.8 \%$ were using email to contact other healthcare professionals (Brooks 2006).

Communication between healthcare professionals occurs in various settings. In primary care, email is routinely used by healthcare professionals to communicate within and between institutions about a range of issues, from diagnoses to logistical issues. Messages can convey multiple topics and can be sent to several recipients (Stiles 2007). Healthcare professionals can use email to request prescriptions from pharmacists; in the US this has been shown to reduce the enquiries pharmacists make about handwritten prescriptions (Podichetty 2004).

Email can also provide a facility for referring patients; it allows requests to be sent between clinicians or their offices quickly, and clerical staff can be integrated into the system to maintain records of referrals (Kassirer 2000). It can also be used to obtain information from staff at hospital laboratories, for instance to obtain test results (Couchman 2005).

For surgeons practising in remote locations internationally, email communication can create valuable access to outside opinion, since it allows low-cost communication of photographic images. More traditional methods have included using the telephone or fax machines, but email can offer a richness of communication that these methods cannot. Digital photographs for diagnosis have proven useful in several fields of surgery (Stutchfield 2007). Similar systems have been used for surgical pre-screening to guide referral to relevant centres outside of remote areas, or to provide prior information for visiting surgeons travelling to remote areas of the world (Lee 2003). It can be used in areas of conflict such as the Middle East to support local doctors and improve healthcare (Patterson 2007).

Public health systems rely on healthcare professionals' reporting of data on disease outbreaks in order to respond and plan accordingly. Laboratory reporting has seen improved notification rates of late, but the maintenance of good communication is vital (Ward 2008) and many healthcare professionals typically fail to comply because of a lack of information and reminders (Voss 1992). Email communication can offer a method of reminding healthcare professionals about notification, and provide links to websites with the appropriate forms and a list of notifiable diseases.

\section{Advantages and disadvantages}

The key advantages of email for clinical communication between healthcare professionals include the following (adapted from Freed 2003; Car 2004a).

- Timely and low cost delivery of information (relative to conventional mail) (Houston 2003).

- Convenience: emails can be sent and subsequently read at an opportune time, outside of traditional office hours where convenient (Leong 2005).

- 'Read receipts' can be used to confirm that communications have been received.

- Relative to oral communication, the written nature of the communication can be valuable as reference for the recipient, aiding recall and providing evidence of the exchange (Car 2004a; Car 2004b).

- Emails can be archived in online or offline folders separate from the inbox of the email account so that they do not use up space in the inbox but can be kept for reference (Car 2004a; Car 2004b).

- Email networks allow the wide dissemination of information amongst a specific group of professionals (Thede 2007).

- Digital images can be transferred easily and quickly between healthcare professionals (Stutchfield 2007).

- Email's convenience facilitates communication among healthcare professionals that may otherwise not occur (Stiles 2007), thus extending the breadth of communication.

There are, however, some potential downsides:

- There is evidence of concerns regarding privacy, confidentiality and potential misuse of information when healthcare professionals communicate via email (Harris 2001; Kleiner 2002; Moyer 2002; Katzen 2005).

- Physicians may be wary of the potential for email to generate an increased workload, as a consequence of the depth of content permitted by this method of communication (Podichetty 2004).

- Potential medico-legal issues (including informed consent and use of non-encrypted email) exist when communicating information about a patient via email (Bitter 2000).

- Email is not appropriate for all communication situations, particularly those requiring urgency since email may not be read immediately upon receipt (Stiles 2007).

- Email as a communication tool provides a different context for interaction. The various layers of communication experienced during a face-to-face encounter or a telephone call are lost in an email; for example the emotive cues from vocal 
intonation or body language (Car 2004a).

- Technological issues may occur, such as recipients having a full inbox causing email to bounce back to the sender (Virji 2006).

- Systems may be at risk of failure, for instance a loss of the link to a central server (a computer which provides services used by other computers, such as email) (Car 2008). There may be several causes for technological system failure; from local power failure to natural disasters.

- The potential for human error can lead to unintended content or incorrect recipients.

\section{Quality and safety issues}

The main quality and safety issues around email communication include: confidentiality, potential for errors and ensuing liability, identifying clinical situations where email communication between healthcare professionals is inefficient or inappropriate, incorporating email into existing work patterns and achievable costs (Kleiner 2002; Gaster 2003; Gordon 2003; Hobbs 2003; Houston 2003; Car 2004b).

Privacy and confidentiality are a formidable challenge in the adoption of email communication (Couchman 2001; Moyer 2002). Web messaging systems can address issues around security and liability that are associated with conventional email communication, since they offer encryption capability and access controls (Liederman 2003). However not all healthcare institutions are capable of providing such a facility, and rely instead on standardised mail (Car 2004b).

Medico-legal issues that are of substantial concern when implementing email communication in practice include potential liability for breaches in security allowing a third party to access confidential medical information, and the possibility of identity fraud (Moyer 1999; Couchman 2001; Car 2004b).

Suggestions for minimising the legal risks of using email in practice have included adherence to the same strict data protection rules that must be followed in business and industry, and adequate infrastructure to provide encrypted secure email transit and storage (Car 2004b).

Education and training results in capable and competent end-users of any technology. This can be costly and time consuming, but enhances the chance of effective implementation of such systems and thus should be a priority. As well as the requirement for initial training, ongoing support is usually necessary to ensure continuing use and further development (Car 2008). A UK-based survey showed that clinicians more recently-qualified feel comfortable using the Internet (Potts 2002). This is unsurprising given the relatively recent introduction of such technologies, and illustrates a potential generational effect on their use. This may influence training needs and the types of demographic groups leading the use of this technology.
We aimed to investigate these issues further in the context of the studies included in this review.

\section{Forms of electronic mail}

In the absence of a standardised email communication infrastructure in the healthcare sector, email has been adopted in an ad-hoc fashion and this has included the use of unsecured and secured email communication.

Standard unsecured email is email which is sent unencrypted. Secured email is encrypted; encryption transforms the text into an un-interpretable format as it is transferred across the Internet. Encryption protects the confidentiality of the data, however both sender and recipient must have the appropriate software for encryption and decoding (TechWeb Network 2008).

Secure email also includes various specifically-developed applications which utilise web messaging. Such portals provide pro-formas into which users can enter their message. The message is sent to the recipient in the manner of an email (TechWeb Network 2008).

Secure websites are distributed by secure web servers. Web servers store and disseminate web pages. Secure servers ensure data from an Internet browser is encrypted before being uploaded to the relevant website. This makes it difficult for the data to be intercepted and deciphered (TechWeb Network 2008).

There are significant differences in terms of the applications. Bespoke secure email programmes may incorporate special features such as standard forms guiding the use and content of the email sent, ability to show read receipts (in order to confirm the addressee has received the correspondence) and, if necessary, facilities for receiving payment (Liederman 2005). However they are costly to set up and may require a greater degree of skill on the part of the user than standard unsecured email (Katz 2004). For the purpose of the review we included all forms of email although secured versus unsecured email was to be considered in a subgroup analysis.

\section{Methods of accessing email}

Methods of accessing the Internet and thus an email account have changed with time.Traditionally access was via a personal computer or laptop at home or work, connecting to the Internet using a fixed line. There are now several methods of accessing the Internet. Wireless networks (known colloquially as wifi) allow Internet connection to a personal computer, laptop computer or other device wherever a network is available (TechWeb Network 2008). Internet connection is also possible via alternative networks using mobile devices. This includes access via mobile telephones to a wireless application protocol (WAP) network (rather than to the world wide web) or to the third generation (3G) network. Adaptors connecting to a universal serial bus (USB) port can be used to access the 3G network using a laptop computer (TechWeb Network 
2008). Therefore email can be accessed away from the office or home in a variety of ways.

For the purposes of the review we included all access methods.

\section{O B J E C T IVES}

To assess the effects of healthcare professionals using email to communicate clinical information, on healthcare professional outcomes, patient outcomes, health service performance, and service efficiency and acceptability, when compared to other forms of communicating clinical information.

\section{METHODS}

\section{Criteria for considering studies for this review}

\section{Types of studies}

We included randomised controlled trials (RCTs), quasi-randomised trials, controlled before and after studies (CBA) with at least two intervention and two control sites, and interrupted time series (ITS) with at least three time points before and after the intervention.

Due to the practicalities of organisational change in a healthcare environment, it can be difficult to randomise studies and thus we included quasi-randomised trials and CBAs. ITS studies are potentially valuable in assessing the ongoing merits of a new technology which may required a 'settling in' period. We included trials with individual and cluster randomisation, and relevant trials with economic evaluations.

\section{Types of participants}

We included all healthcare professionals regardless of age, gender and ethnicity. We included studies in all settings i.e. primary care settings (services of primary health care), outpatient settings (outpatient clinics), community settings (public health settings) and hospital settings. We did not exclude studies according to the type of healthcare professional (e.g. surgeon, nurse, doctor, allied staff). We considered participants originating the email communication, receiving the email communication and copied into the email communication.

\section{Types of interventions}

We included studies in which email was used for two-way clinical communication between healthcare professionals to facilitate inter-service consultation. We included interventions that used email to allow healthcare professionals to contact each other, for example to send information about a patient, to provide notifications for public health purposes, or to facilitate the sharing of relevant information about the healthcare institution.

We included interventions that used email in any of the following forms for communication between healthcare professionals:

1. Unsecured standard email to/from a standard email account.

2. Secure email which is encrypted in transit and sent to/from a standard email account with the appropriate encryption decoding software.

3. Web messaging, whereby the message is entered into a proforma which is sent to a specific email account, the address of which is not available to the sender.

We included all methods of accessing email, including broadband via a fixed line, broadband via a wireless connection, connecting to the $3 \mathrm{G}$ network and connecting to the WAP network.

We excluded studies of email between professionals solely for educational purposes. We excluded studies which considered the general use of email for communication between healthcare professionals for multiple purposes but did not separately consider clinical communication between healthcare professionals. Studies where email was one part of a multifaceted intervention were included where the effects of the email component were individually reported, even if they did not represent the primary outcome. However these were only considered where they achieved the appropriate statistical power. Where this could not be determined or where it was not possible to separate the effects of the multifaceted intervention they were not included.

We included studies comparing email communication to no intervention, as well as comparing it to other modes of communication such as face-to-face, postal letters, calls to a landline or mobile telephone, text messaging using a mobile telephone, and if applicable, automated versus personal emails.

\section{Types of outcome measures}

Primary outcomes of interest focussed on whether the email has been understood and acted upon correctly by the recipient as intended by the sender, and secondary outcomes focussed on whether email was an appropriate mode of communication.

\section{Primary outcomes}

Healthcare professional outcomes resulting from whether the email has been understood and acted upon correctly by the recipient as intended by the sender, e.g. professional knowledge and understanding, inter-professional communication and relationships, professional behaviour, actions or performance.

Patient outcomes associated with whether the email has been understood and acted upon correctly by the recipient as intended by the sender, such as patient understanding, patient health status 
and well-being, treatment outcomes, skills acquisition, support, patient behaviours or actions.

Health service outcomes associated with whether email has been understood and acted upon correctly by the recipient as intended by the sender, e.g. service use, management or coordination of a health problem.

Harms e.g. effects on safety or quality of care, breaches in privacy, technology failures.

\section{Secondary outcomes}

Professional, patient or carer outcomes associated with whether email was an appropriate mode of communication, e.g. knowledge and understanding, effects on professional or professionalcarer communication, evaluations of care (such as convenience, acceptability, satisfaction).

Health service outcomes associated with whether email was an appropriate mode of communication, e.g. use of resources or time, costs.

\section{Search methods for identification of studies}

\section{Electronic searches}

We searched:

- Cochrane Consumers and Communication Review Group Specialised Register (searched January 2010)

- Cochrane Central Register of Controlled Trials

(CENTRAL, The Cochrane Library Issue 1, 2010) (searched January 2010)

- MEDLINE (OvidSP) (1950 to January 2010)

- EMBASE (OvidSP) (1980 to January 2010)

- PsycINFO (OvidSP) (1967 to January 2010)

- CINAHL (EbscoHOST) (1982 to January 2010)

- ERIC (CSA) (1965 to January 2010)

We present detailed search strategies in Appendices 1 to 5. John Kis-Rigo, Trials Search Coordinator for the Cochrane Consumers and Communication Group, compiled the strategies.

There were no language or date restrictions.

\section{Searching other resources}

\section{Grey Literature}

We searched for grey literature via theses and dissertation repositories, trials registers and Google Scholar.

We searched using the following sources:

- Australasian Digital Theses Program (http:// adt.caul.edu.au/) (searched July 2010)
- Networked Digital Library of Theses and Dissertations (http://www.ndltd.org) (searched July 2010)

- UMI ProQuest Digital Dissertations (http://

wwwlib.umi.com/dissertations/) (searched July 2010)

- Index to Theses (http://www.theses.com/) (Great Britain and Ireland) (searched July 2010)

- Clinical trials register (Clinicaltrials.gov) (searched July 2010)

- WHO Clinical Trial Search Portal (www.who.int/ trialsearch) (searched July 2010)

- Current Controlled Trials (www.controlled-trials.com) (searched July 2010)

- Google Scholar (http://scholar.google.co.uk/) (we examined the first 500 hits) (searched July 2010)

We searched online trials registers for ongoing and recently completed studies and contacted authors where relevant. We kept detailed records of all the search strategies applied.

\section{Reference lists}

We examined the reference lists of retrieved relevant studies.

\section{Correspondence}

We contacted the authors of included studies for advice as to any further studies or unpublished data that they were aware of. Many of the authors of included studies were also experts in the field.

\section{Data collection and analysis}

\section{Selection of studies}

Two review authors (HA and PS) independently assessed the potential relevance of all titles and abstracts identified from electronic searches. We retrieved full text copies of all articles judged to be potentially relevant. Both HA and PS independently assessed these retrieved articles for inclusion. Where HA and PS could not reach consensus a third author, YP, examined these articles.

During a meeting of all review authors, we verified the final list of included and excluded studies. Any disagreements about particular studies were resolved by discussion. Where the description of a study was insufficiently detailed to allow us to judge whether it met the review's inclusion criteria, we contacted the study authors to obtain more detailed information to allow a final judgement regarding inclusion or exclusion to be made. We have retained detailed records of these communications. 


\section{Data extraction and management}

We extracted data from included studies using a standard form derived from the data extraction template provided by the Cochrane Consumers and Communication Review Group. We extracted the following data:

- General information: Title, authors, source, publication status, date published, language, review author information, date reviewed.

- Details of study: Aim of intervention and study, study design, location and details of setting, methods of recruitment of participants, inclusion/exclusion criteria, ethical approval and informed consent, consumer involvement.

- Assessment of study quality: Key features of allocation, contemporaneous data collection for intervention and control groups; and for interrupted time series, number of data points collected before and after the intervention, follow-up of participants.

- Risk of bias: data to be extracted depended on study design (see Assessment of risk of bias in included studies).

- Participants: Description, geographical location, setting, number screened, number randomised, number completing the study, age, gender, ethnicity, socio-economic grouping and other baseline characteristics, health problem, diagnosis, treatment.

- Intervention: Description of the intervention and control including rationale for intervention versus the control (usual care). Delivery of the intervention including email type (standard unsecured email, secure email, web portal or hybrid). Type of clinical information communicated (e.g. diagnostic test results, information on an individual patient). Content of communication (e.g. text, image). Purpose of communication (e.g. obtaining information, providing information). Communication protocols in place. Who delivers the intervention (e.g. healthcare professional, administrative staff). How consumers of interventions are identified. Sender of first communication (health service, professional, patient and/or carer). Recipients of first communication (health service, professional, patient and/or carer). Whether communication is responded to (content, frequency, method of media). Any cointerventions included. Duration of intervention. Quality of intervention. Follow up period and rationale for chosen period.

- Outcomes: principal and secondary outcomes, methods for measuring outcomes, methods of follow-up, tools used to measure outcomes, whether the outcome is validated.

- Results: for outcomes and timing of outcome assessment, control and intervention groups if applicable.

HA and PS piloted the data extraction template to allow for unforeseen variations in studies. For the included study both HA and PS independently extracted data. Any discrepancies between the review authors' data extraction sheets were discussed and resolved by HA and PS. Where necessary, we involved YP to resolve discrepancies.

\section{Assessment of risk of bias in included studies}

Two review authors, HA and PS, independently assessed the risk of bias of included studies, with any disagreements resolved by discussion and consensus, and by consulting a third author, YP, where necessary.

We assessed and reported on the following elements that contribute to bias, according to the guidelines outlined in Higgins 2008:

- Sequence generation;

- Allocation concealment;

- Blinding (participants, personnel, outcomes assessors, data analysers);

- Intention-to-treat analysis;

- Incomplete outcome data;

- Selective outcome reporting.

We assigned a judgement relating to the risk of bias for each item. We used a template to guide the assessment of risk of bias, based upon the guidance by Higgins 2008, judging each item as low, unclear or high risk of bias. We summarised risk of bias for each outcome where this differed within studies.

We also assessed a range of other possible sources of bias and indicators of study quality, in accordance with the guidelines of the Cochrane Consumers and Communication Review Group (Ryan 2007), including:

- Baseline comparability of groups;

- Validation of outcome assessment tools;

- Reliability of outcome measures;

- Other possible sources of bias

We present the results of the risk of bias assessment in tables and have incorporated the results of the assessment of risk of bias into the review through systematic narrative description and commentary about each of the quality items. This has led to an overall assessment of the risk of bias across the included studies and a judgement about the possible effects of bias on the effect sizes of the included studies.

We contacted the study author for additional information about the included study, obtaining clarification on the study methods.

\section{Measures of treatment effect}

For dichotomous data, when outcomes were measured in a standard way, we reported the odds ratio/risk ratio and confidence intervals. For continuous data, where outcomes were measured in a standard way across studies, we reported the mean values for the intervention versus control group. It was not possible to calculate a mean difference and confidence intervals because standard deviations were not available and the data required to calculate these (mean difference, sample size and standard error values) were not available. We therefore present data as per the published report. 


\section{Data synthesis}

As we identified only one study it was not possible to conduct a quantitative meta-analysis. The methods that we would have applied had data analysis and pooling been possible are outlined in Appendix 1 and will be applied to future updates of the review.

\section{Consumer input}

We asked two consumers, a health services researcher (UK) and healthcare consultant (Saudi Arabia) to comment on the completed review before submitting the review for the peer-review process, with a view to improving the applicability of the review to potential users. The review also received feedback from two consumer referees as part of the Cochrane Consumers and Communication Review Group's standard editorial process.

\section{RES U L T S}

\section{Description of studies}

See: Characteristics of included studies; Characteristics of excluded studies; Characteristics of ongoing studies.

\section{Results of the search}

As this review was one in a set of five looking at varying uses of email in health care, we conducted a common search for all five reviews (Atherton 2009a; Atherton 2009c; Atherton 2012 in press; Meyer 2012). Relevant studies were allocated to each review after being assessed at the full text stage. Figure 1 shows the search and selection process. 
Figure I. Flow diagram illustrating search results.

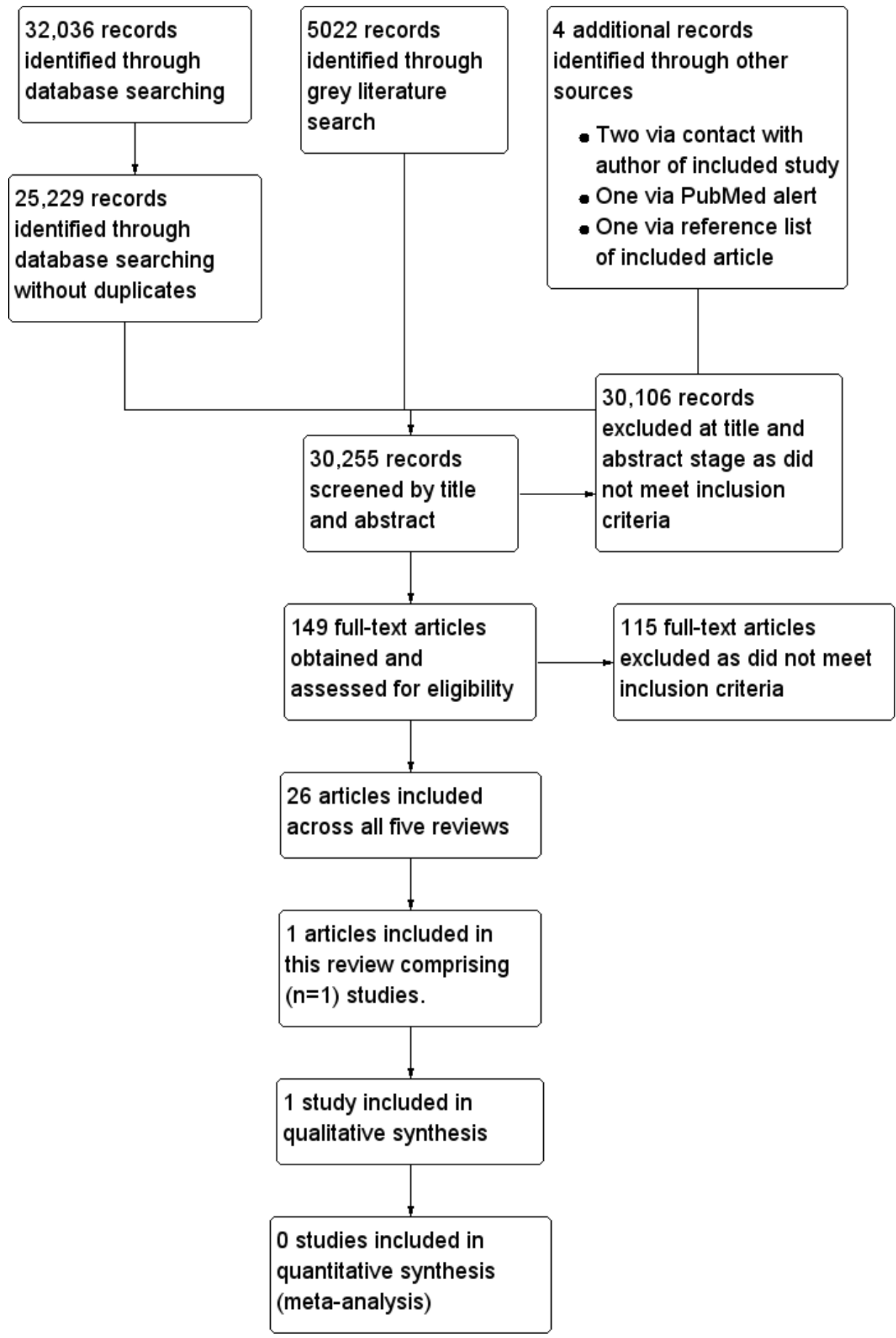




\section{Included studies}

We included one randomised controlled trial involving 327 patients and 159 primary care providers at baseline. (Feldstein 2006, see also Characteristics of included studies). The trial assessed two intervention groups (electronic medical record (EMR) reminder and EMR reminder plus patient reminder) and one control group (usual care pathway). For the purposes of this review we were interested in the comparison between the EMR reminder group and the usual care group. Feldstein 2006 estimated that 100 patients per group were needed to have a $80 \%$ chance of detecting an effect size of 0.40 . Three hundred and twenty seven female patients were randomised across three groups, and after drop outs there were 101 in the usual care group, 101 in the EMR reminder group and 109 in the EMR reminder + patient reminder. We only report data from the usual care and EMR reminder group in the review.

This US study was set in a Pacific Northwest, non-profit, health maintenance organisation (HMO) with about 454,000 members. Randomised women were aged 50 to 89 , had suffered a fracture in 1999 and had not received bone mineral density (BMD) measurement or medication for osteoporosis. The intervention was delivered to the primary care physicians of the randomised female patients. All healthcare professionals within the HMO had access to an EMR-based email account with the capacity to reply to messages received.

\section{Interventions}

The purpose of the intervention was to increase guideline-recommended osteoporosis treatment. Primary care providers in both intervention arms (EMR and EMR + patient reminder) received patient-specific EMR 'in-basket' messages for their enrolled patients from the chairman of the osteoporosis quality-improvement committee. 'In basket' messages are an EMR-based email communication used exclusively for patient care activities.

The letter-style message informed the provider of the patient's risk of osteoporosis based upon the patient's age and prior fracture, and stated the need for evaluation and treatment. Three months later, a reminder (specific to individual patients) was sent to primary care providers who had not ordered a BMD measurement or pharmacological osteoporosis treatment for enrolled patients. The provider could contact the message sender for additional information.
Patients in the usual care arm continued to receive care at the HMO through the normal pathway.

\section{Outcomes}

The study examined both primary and secondary outcomes relevant to this review.

\section{Health professional outcomes}

This study reported health professional actions and performance in terms of whether the care provider ordered a bone mineral density measurement, and/or prescribed osteoporosis medication, to women who had suffered a fracture.

\section{Patient outcomes}

This study reported the primary outcome of patient behaviours, in terms of the effect on women's calcium intake, regular activity and calorific expenditure, and the secondary outcome of evaluation of care in terms of satisfaction with care and services received for bone health.

\section{Health service outcomes}

No outcomes relating to health services are reported in the study. Harms

No outcomes relating to harms are reported in the study.

\section{Excluded studies}

We excluded eleven studies from the review (see Characteristics of excluded studies table). We excluded eight of these because they concerned one-way rather than two-way communication between healthcare professionals (Lester 2004; Feldman 2005; Mandall 2005; Lester 2006; Edward 2007; Ward 2008; Johansson 2009; Chen 2010). In three studies, email was part of a multifaceted intervention and the email component was not assessed separately (Jaatinen 2002; Persell 2008; Ward 2008). One study concerned communication for educational purposes (Murtaugh 2005).

\section{Risk of bias in included studies}

The risk of bias ratings were based on the published report and contact with the author of the study to obtain further information where aspects of the trial methodology were unclear.

Figure 2 summarises the risk of bias for the included study. Further details can be found in the Characteristics of included studies table. 
Figure 2. Risk of bias summary: review authors' judgements about each risk of bias item for each included study.

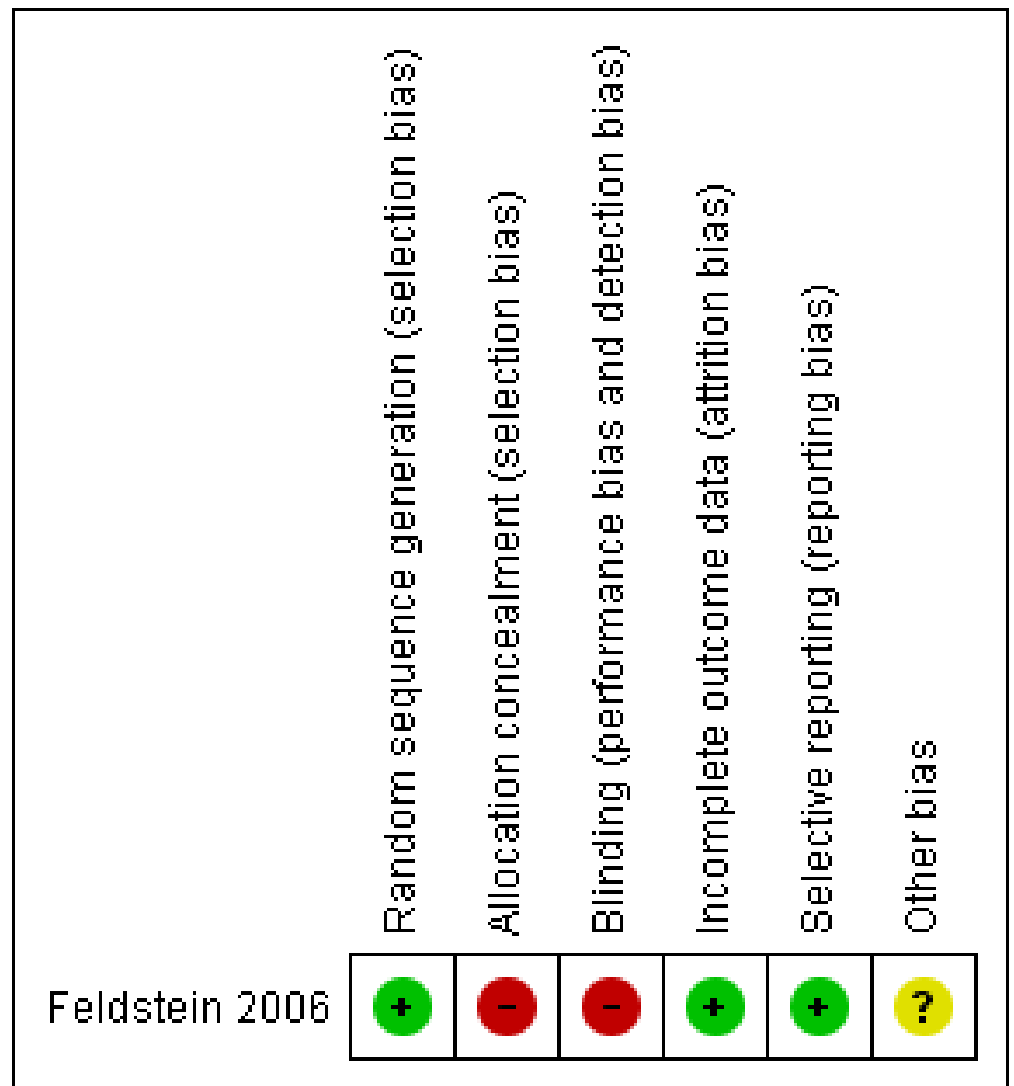

\section{Allocation}

A computer random-number generator was used to produce the random sequence. We judged allocation concealment to be inadequate. The study report does not describe the method of concealment, and the author confirmed that the person allocating could tell which group the participants were assigned to.

\section{Blinding}

Neither the study nurse conducting the interventions nor the participants (providers or patients) were blinded to group assignment. However the study analyst assessing the outcomes was blinded to the treatment groups.

\section{Incomplete outcome data}

Incomplete outcome data were adequately addressed.

\section{Selective reporting}

There was no evidence of selective reporting in this study.

\section{Other potential sources of bias}

There were some other sources of bias in this study, but the overall consensus was that the risk of bias was unclear. Some instruments used to measure the outcomes were not validated, and some may have been subject to reliability issues. An example is patientcompleted questionnaires concerning activity and calorific expenditure. Such questionnaires are more at risk from reporter bias, that is, the participant gives the answers they believe they should according to social norms, rather than their true answers.

\section{Effects of interventions}

We report the effects of interventions on primary and secondary outcomes (see Data and analyses) for the included study, Feldstein 
2006. We only report data for the EMR message group versus the usual care group.

\section{Primary Outcomes}

\section{Health professional actions or performance}

Reported outcomes relating to healthcare professional actions or performance all favoured the EMR intervention.

Patients whose physicians received the EMR message were more likely to receive the recommended care than those in the usual care group; specifically, a bone mineral density (BMD) measurement (OR 31.17; 95\% CI 4.13 to 235.51); a BMD measurement or osteoporosis medication (OR 16.80; 95\% CI 6.75 to 41.85); or osteoporosis medication only (OR 3.27; 95\% CI 1.02 to 10.51 ). Those in the usual care group were more likely to receive neither a BMD measurement nor osteoporosis medication (OR 0.06; 95\% CI 0.02 to 0.15 ) (see Analysis 1.1; Analysis 1.2; Analysis 1.3; Analysis 1.4).

The study included a regression model adjusted for fracture type, age, weight less than 127 pounds, diagnosis of osteoporosis and Charlson Comorbidity Index, to predict the probability of a patient receiving the recommended care. The EMR reminder increased the probability of receiving a BMD measurement and/or osteoporosis medication (see Analysis 1.5; Analysis 1.6; Analysis 1.7).

\section{Patient behaviour}

The study examined three measures relating to patient behaviours. The results favoured the intervention for all measures, but the difference was only significant for one measure.

Pre- and post-intervention measurements in each group indicated that the women whose physicians received the EMR message had a higher calcium intake ( $194.9 \mathrm{mg} /$ day) after the intervention, but those in the usual care group had a reduced calcium intake $(-457.4$ $\mathrm{mg} /$ day) after the intervention.

For regular activity the mean number of participants engaging in activity long enough to break a sweat at least once a week was reduced for the intervention group (-1) and increased in the usual care group (3). For calorific expenditure this was increased in both groups; EMR (770.2 Kcal) and usual care $(344.8 \mathrm{Kcal})$.

The study authors carried out comparison tests for all of these measures and found that there was a significant difference between the EMR and usual care groups for calcium intake $(P=0.02)$ but there was no significant difference between groups for reporting regular activity $(P=0.17)$ and calorific expenditure $(P=0.96)$.

\section{Health service outcomes}

No primary outcomes relating to health services were assessed in the included study.

\section{Harms}

No primary outcomes relating to harms were assessed in the included study

\section{Secondary Outcomes}

\section{Patient evaluation of care}

The study examined one measure of evaluation of care, namely mean change in satisfaction with care and services received for bone health. The EMR group had a positive mean change from baseline (0.07) in satisfaction with care and the usual care group had a negative mean change from baseline (-0.07). The differences between groups were reported as non-significant by the authors. No other secondary outcomes were reported.

\section{DISCUSSION}

\section{Summary of main results}

This review contains only one study and this study was at unclear to high risk of bias. Therefore the reported results should be viewed with caution.

The primary outcomes of interest related to whether the email had been understood and acted upon correctly by the recipient, as intended by the sender.

The study compared an electronic medical record (EMR) reminder with usual care. There was evidence that the EMR reminder changed professional actions in a positive way compared to those in the usual care group. The evidence for patient behaviour was inconclusive, with one measure finding that the EMR message impacted patient behaviour positively and two finding no difference between the two groups. No primary health service outcomes or harm outcomes were measured in the included study.

The secondary outcomes of interest were whether email was an appropriate mode of communication. Patient evaluation of care showed a positive increase in favour of the intervention, based on the reported data. However, it was not possible to calculate a mean difference and the study authors did not carry out a test for comparison between groups, and so this evidence is inconclusive. No other secondary outcomes were reported.

Based on the findings of this review, it is not possible to determine the benefits of email for clinical communication between healthcare professionals. The nature of the evidence base means that we are uncertain about the majority of primary and secondary outcomes.

\section{Overall completeness and applicability of evidence}


With only one study in the review (Feldstein 2006), the findings are incomplete with regard to outcome measures and the applicability of evidence. There were no health service outcomes or outcomes relating to harms reported in this review.

The identification of only one relevant study means that the review's applicability to other settings is minimal. The included study featured a specific type of email; an Internet portal comprising the electronic medical record, with an 'in basket' message function. The email sent to healthcare professionals concerned management of a specific condition (osteoporosis) in particular patients (those having had a fracture). Healthcare professionals could respond if they required further information, but response was not measured. This web portal type of email is very different to standard email, which we might have expected to see being used as a tool for more generic two-way communication.

As well as targeting specific types of patient and condition, the included study was set in a HMO in the United States (US), a high income country with English as the predominant language. The US has a mixed healthcare system with both government and insurance-based coverage schemes. The findings may not be applicable outside this setting.

In addition, the study was carried out in 2006. Developments in technology have occurred since then such as the rise of 'smartphones'. The rapid spread of the Internet has changed the landscape with regard to technology use in society. These changes pose a problem for any reviews of evidence concerning Internet based technologies.

\section{Quality of the evidence}

The included study had unclear to high risk of bias, with a high risk of bias for allocation concealment and blinding status. There was an uncertain risk of other types of bias; this was because we were unable to obtain some details about the study despite contact with the author .

\section{Potential biases in the review process}

\section{Searches}

As well as database searches we conducted an extensive search of the grey literature which helped to ensure that we did not miss ongoing studies and dissertation theses. Terminology is an ongoing problem when searching for evidence on new technologies, especially those used for communication. Several different terms can be used to describe email, including electronic mail, electronic messaging, web messaging, and web consultation. Our searches used a wide selection of terms and their truncations to ensure that all variations were found. However we may have missed other relevant terms. The changing nature of terms for technology should be considered in any future update of this review.
The date of the search is a limitation of this review. The search was conducted in January 2010, and it is possible that relevant studies have been published since then. To counter this, the review will be updated in the near future.

As we were unable to produce funnel plots, it was not possible to ascertain the likelihood of publication bias for individual outcomes. Despite our sensitive search strategy, it is possible data were unavailable to us. For instance, if companies have carried out trials and found these results to be negative or equivocal, they may choose not to publicise these results. The need for trial registration may not be apparent to corporations embarking on their first trials.

\section{Scope of the review}

The broad question addressed in this review and the wide-ranging criteria used for studies, participants, interventions, and outcome measures will have ensured that studies were not unnecessarily excluded. However restricting the review to studies of twoway communication led to the exclusion of several studies where email was used in a one-way fashion. These included a study of email used to provide discharge summaries (Chen 2010) and another for referring patients for orthodontic treatment (Mandall 2005). Several studies attempted to influence health professional behaviour via email with regard to prescribing behaviours (Lester 2006; Edward 2007; Persell 2008), reporting of adverse drug reactions (Johansson 2009) and diseases (Ward 2008) and provision of health care (Lester 2004; Feldman 2005; Murtaugh 2005).

These studies could be deemed relevant for a separate review considering email use between healthcare professionals for administrative purposes (e.g. discharge summaries, disease reporting and referral) or a review considering email for delivering material that facilitates changes in practice (e.g. prescribing behaviour) though this may have some overlap with reviews that consider behavioural interventions. They could also be included in a future update of this review.

Unlike interventions with a directly measurable impact on health (drug treatments, surgical procedures), email is a complex intervention and its potential impact may come from any number of factors. A complex intervention is that with several interacting components. The complexity can have several dimensions; these may include the organisational levels targeted by the intervention (administrative staff, nurses, doctors, management) or degree of flexibility or tailoring of the intervention permitted (standard email allowing free text, web-based systems with a pro-forma for entering text) (Craig 2008). As a consequence of this complexity it may be more difficult to determine what should be tested and how, and doing this in the context of a controlled trial may be perceived as difficult. We decided to include other types of study designs as well as randomised controlled trials in this review, but only one randomised controlled trial was identified.

Possible reasons for the lack of studies meeting the inclusion cri- 
teria may be that studies approaching the use of email between healthcare professionals are firstly concerned with solutions relating to individual diseases (e.g. osteoporosis) rather than as email itself as an intervention. In addition we must consider that for some purposes specific functionality has been developed that facilitates health professional communication. In the UK, the Electronic Prescription Service run by the NHS 'enables prescribers to send prescriptions electronically to a dispenser (such as a pharmacy) of the patient's choice' (NHS Connecting for Health 2011). The development and proliferation of sophisticated and tailored software may have negated the need to use email with its associated disadvantages; such privacy and security concerns.

Conversely, day-to-day communication between healthcare professionals may not be deemed an intervention in the same way it would be if used with a patient. Especially when we consider that email is used extensively in the workplace in many sectors, the impact on patients of day-to-day contact between healthcare professionals may not have been considered or deemed important.

\section{Agreements and disagreements with other studies or reviews}

We are not aware of any other reviews addressing the use of email between healthcare professionals. The limited literature on communication between healthcare professionals via email consists of brief reports of systems in use in clinical practice (Dhillon 2010), and discussions that include normative suggestions of how such communication could be used effectively (Thede 2007; Lomas 2008). There is consensus that email has the potential to facilitate communication between healthcare professionals (Lomas 2008; Abujudeh 2009) but effective implementation is subject to incorporating emails into allocated administration times (Dhillon 2010). Issues around workload and administration were not addressed in the included study.

\section{AUTHORS' CONCLUSIONS}

\section{Implications for practice}

No recommendations for practice can be made given the current lack of evidence of benefit (or harm).

\section{Implications for research}

This review highlights the need for high-quality studies, preferably randomised controlled trials, to evaluate the effects of using email for clinical communication between healthcare professionals. Future studies need to be rigorous in design and delivery, with subsequent reporting to include high-quality descriptions of all aspects of methodology to enable appraisal and interpretation of results. Prompting the development of such trials may involve addressing the barriers to trial development and implementation, and addressing any perception that studies of health professional communication and associated effects are unnecessary.

We have highlighted the possible reasons why there may be a lack of evidence in this review. With regard to further research, we think it would be beneficial to consider what researchers wish to measure in carrying out trials. A version of the 'digital divide' has been observed amongst healthcare professionals whereby time since qualification can influence opinions of technologies like the Internet (Potts 2002). Any study design should allow for analysis of possible variation of effect by age and time since qualification. Physician-related concerns to be considered would be factors such as the security of email messaging and workload concerns (Car 2004b). At the moment these factors are not addressed in the evidence base.

\section{ACKNOWLEDGEMENTS}

We thank the staff and editors of the Cochrane Consumers and Communication Review Group, especially Sophie Hill and Megan Prictor for their prompt and helpful advice and assistance.

We thank John Kis-Rigo, Trials Search Co-ordinator, Cochrane Consumers and Communication Group for compiling the search strategy.

We thank the authors of Car 2012, de Jongh in press, GurolUrganci 2012 and Vodopivec-Jamsek 2012 in press for the use of their data management and analysis framework.

We thank Carina King and Dr Riyadh Alshamsan for consumer input at the review stage. 


\section{R E F E R E N C E S}

\section{References to studies included in this review}

Feldstein 2006 \{published data only\}

Feldstein A, Elmer PJ, Smith DH, Herson M, Orwoll E, Chen $\mathrm{C}$, et al.Electronic medical record reminder improves osteoporosis management after a fracture: a randomized, controlled trial. Journal of the American Geriatrics Society 2006;54(3):450-7.

\section{References to studies excluded from this review}

\section{Chen 2010 \{published data only\}}

Chen Y, Brennan N, Magrabi F. Is email an effective method for hospital discharge communication? A randomized controlled trial to examine delivery of computer-generated discharge summaries by email, fax, post and patient hand delivery. International Journal of Medical Informatics 2010; 79(3):167-72.

Edward 2007 \{published data only\}

Edward C, Himmelmann A, Wallerstedt SM. Influence of an e-mail with a drug information attachment on sales of prescribed drugs: a randomized controlled study. $B M C$ Clinical Pharmacology 2007;7:7-12.

Feldman 2005 \{published data only\} Feldman PH, Murtaugh CM, Pezzin LE, McDonald MV, Peng TR. Just-in-time evidence-based e-mail "reminders" in home health care: impact on patient outcomes. Health Services Research 2005;40(3):865-85.

Jaatinen 2002 \{published data only\} Jaatinen PT, Aarnio P, Remes J, Hannukainen J, Köymäri ST. Teleconsultation as a replacement for referral to an outpatient clinic. Journal of Telemedicine and Telecare 2002; 8:102-6.

Johansson 2009 \{published data only\}

Johansson M-L, Brunlof G, Edward C, Wallerstedt SM. Effects of e-mails containing ADR information and a current case report on ADR reporting rate and quality of reports. European Journal of Clinical Pharmacology 2009;65 (5):511-4.

Lester 2004 \{published data only\} Lester WT, Grant R, Barnett GO, Chueh H. Facilitated lipid management using interactive e-mail: preliminary results of a randomized controlled trial. Studies in Health Technology and Informatics 2004;107:232-6.

Lester 2006 \{published data only\}

Lester WT, Grant RW, Barnett GO, Chueh HC. Randomized controlled trial of an informatics-based intervention to increase statin prescription for secondary prevention of coronary disease. Journal of General Internal Medicine 2006;21:22-9.

Mandall 2005 \{published data only\}

Mandall NA, O'Brien KD, Brady J, Worthington HV, Harvey L. Teledentistry for screening new patient orthodontic referrals. Part 1: A randomized controlled trial. British Dental Journal 2005;199:659-62.
Murtaugh 2005 \{published data only\}

Murtaugh CM, Pezzin LE, McDonald MV, Feldman PH, Peng TR. Just in-time evidence based e-mail "reminders" in home health care: impact on nurse practices. Health Services Research 2005;40(3):849-64.

Persell 2008 \{published data only\}

Persell SD, Denecke-Dattalo TA, Dunham DP, Baker DW. Patient-directed intervention versus clinician reminders alone to improve aspirin use in diabetes: a cluster randomized trial. Joint Commission Journal on Quality and Patient Safety / Joint Commission Resources 2008;34(2): 98-105.

Ward 2008 \{published data only\} Ward LD, Spain CV, Perilla MJ, Morales KH, Linkin DR. Improving disease reporting by clinicians: the effect of an internet-based intervention. Journal of Public Health Management and Practice 2008;14(1):56-61.

\section{References to ongoing studies}

\section{Cline 2007 \{published data only\}}

Cline D, Ayala C, Caskie D, Ferrario C. Patient specific feedback increases referral of hypertensive emergency department patients: a randomized controlled trial. Society for Academic Emergency Medicine Annual Meeting. Academic Emergency Medicine 2007;14(7):S117.

\section{Dalal NCT01153451 \{unpublished data only\}}

An Automatic Notification System for Test Results Finalized After Discharge.. Ongoing study July 2010.

\section{Additional references}

Abujudeh 2009

Abujudeh HH, Kaewlai R, Choy G, Whelton DG, Rosenthal DI. Important imaging finding e-mail alert system: experience after 3 years of implementation. Radiology 2009;252(3):747-53.

Alderson 2002

Alderson P, Green S. Issues related to the unit of analysis. http://www.cochrane-net.org/openlearning/html/ $\operatorname{modA2}$.htm 2002.

\section{Atherton 2009a}

Atherton H, Car J, Meyer B. Email for the provision of information on disease prevention and health promotion. Cochrane Database of Systematic Reviews 2009, Issue 3. [DOI: $10.1002 / 14651858 . C D 007982]$

\section{Atherton 2009c}

Atherton H, Car J, Meyer B. Email for clinical communication between patients/caregivers and healthcare professionals. Cochrane Database of Systematic Reviews 2009, Issue 3. [DOI: 10.1002/14651858.CD007978]

\section{Atherton 2012 in press}

Atherton H, Sawmynaden P, Meyer B, Car J. Email for the coordination of healthcare appointments and attendance 
reminders. Cochrane Database of Systematic Reviews 2012, Issue in press.

\section{Bitter 2000}

Bitter J. E-mail in medical practice: legal and ethical concerns. QRC Advisor 2000;16(3):1-8.

\section{Brooks 2006}

Brooks RG, Menachemi N. Physicians' use of email with patients: factors influencing electronic communication and adherence to best practices. Journal of Medical Internet Research 2006;8(1):e2.

\section{Car 2004a}

Car J, Sheikh A. Email consultations in health care: 1 . scope and effectiveness. BMJ 2004;329(7463):435-8.

Car 2004b

Car J, Sheikh A. Email consultations in health care: 2. acceptability and safe application. BMJ 2004;329(7463): 439-42.

Car 2008

Car J, Black A, Anandan C, Cresswell K, Pagliari C, McKinstry B, et al.The impact of EHealth on the quality and safety of healthcare. http://www1.imperial.ac.uk/ resources/4565EF18-662B-448B-90C2-E7372B4C2E09/ 2008.

Car 2012

Car J, Gurol-Urganci I, de Jongh T, Vodopivec-Jamsek V, Atun R. Mobile phone messaging reminders for attendance at healthcare appointments. Cochrane Database of Systematic Reviews 2012, Issue 7.

\section{CBI 2006}

Confederation of British Industry (CBI). Google survey of internet trends for business and consumers. www.cbi.org.uk/pdf/cbigooglesurvey1 106.pdf 2006.

\section{Couchman 2001}

Couchman GR, Forjuoh MD, Samuel N. E-mail communications in family practice: what do patients expect?. The Journal of Family Practice 2001;50(5):414-18.

\section{Couchman 2005}

Couchman GR, Forjuoh SN, Rascoe TG, Reis MD, Koehler B, Walsum KL. E-mail communications in primary care: what are patients' expectations for specific test results? . International Journal of Medical Informatics 2005;74(1): $21-30$.

\section{Craig 2008}

Craig P, Dieppe P, Macintyre S, Michie S, Nazareth I, Petticrew M. Developing and evaluating complex interventions: the new Medical Research Council guidance. BMJ 2008;337:a1655.

\section{de Jongh in press}

de Jongh T, Gurol-Urganci I, Vodopivec-Jamsek V, Car J, Atun R. Mobile phone messaging for facilitating self management of long-term illnesses. Cochrane Database of Systematic Reviews 2012, Issue In press.

\section{Dhillon 2010}

Dhillon J, Shaw NJ. You've got mail: consultant email practice. Archives of Disease in Childhood 2010;95(9):765.

\section{Freed 2003}

Freed DH. Patient-physician e-mail: passion or fashion?. Health Care Manager 2003;22(3):265-74.

\section{Gaster 2003}

Gaster B, Knight CL, DeWitt DE, Sheffield JV, Assefi NP, Buchwald D. Physicians' use of and attitudes toward electronic mail for patient communication. Journal of General Internal Medicine 2003;18(5):385-9.

\section{Gordon 2003}

Gordon C, Krimholtz M. E-mail and patients: a medicolegal minefield. Lancet 2003;362(9397):1768.

\section{Gurol-Urganci 2012}

Gurol-Urganci I, de Jongh T, Vodopivec-Jamsek V, Car J, Atun R. Mobile phone messaging for communicating results of medical investigations. Cochrane Database of Systematic Reviews 2012, Issue 6. [DOI: 10.1002/ 14651858.CD007456.pub2]

\section{Harris 2001}

Harris Interactive. New data show internet, website and email usage by physicians all increasing. www.harrisinteractive.com/news/allnewsbydate.asp? NewsID=1096 2001 .

\section{Higgins 2008}

Higgins JPT, Green S. Cochrane Handbook for Systematic Reviews of Interventions Version 5.0.1. www.cochranehandbook.org. 2008.

\section{Hobbs 2003}

Hobbs J, Wald J, Jagannath YS, Kittler A, Pizziferri L, Volk LA, et al.Opportunities to enhance patient and physician email contact. International Journal of Medical Informatics 2003;70(1):1-9.

\section{Houston 2003}

Houston TK, Sands DZ, Nash BR, Ford DE. Experiences of physicians who frequently use e-mail with patients. Health Communication 2003;15(4):515-25.

\section{IWS 2007}

Internet World Statistics (IWS). World internet usage and population statistics. www.internetworldstats.com/ stats.htm 2007.

\section{Kassirer 2000}

Kassirer JP. Patients, physicians, and the Internet. Health Affairs 2000;19(6):115-23.

\section{Katz 2004}

Katz SJ, Moyer CA. The emerging role of online communication between patients and their providers. Journal of General Internal Medicine 2004;19:978-83.

\section{Katzen 2005}

Katzen C, Solan MJ, Dicker AP. E-mail and oncology: a survey of radiation oncology patients and their attitudes to a new generation of health communication. Prostate Cancer Prostatic Disease 2005;8(2):189-93.

\section{Kleiner 2002}

Kleiner KD, Akers R, Burke BL, Werner EJ. Parent and physician attitudes regarding electronic communication in pediatric practices. Pediatrics 2002;109(5):740-4. 
Lee 2003

Lee S, Broderick TJ, Haynes J, Bagwell C, Doarn CR, Merrell RC. The role of low-bandwidth telemedicine in surgical prescreening. Journal of Pediatric Surgery 2003;38 (9):1281-3.

Leong 2005

Leong SL, Gingrich D, Lewis PR, Mauger DT, George JH. Enhancing doctor-patient communication using email: a pilot study. The Journal of the American Board of Family Medicine 2005;18(3): 180-88.

\section{Liederman 2003}

Liederman EM, Morefield CS. Web messaging: a new tool for patient-physician communication. Journal of the American Medical Informatics Association 2003;10(3): $260-70$.

\section{Liederman 2005}

Liederman EM, Lee JC, Baquero VH, Seites PG. The impact of patient-physician web messaging on provider productivity. The Journal of Healthcare Information Management 2005;19:81-6.

\section{Lomas 2008}

Lomas, E. Inbox health check. He@lth Information on the Internet 2008;66(1):3-5.

\section{Meyer 2012}

Meyer B, Atherton H, Sawmynaden P, Car J. Email for communicating results of diagnostic medical investigations to patients. Cochrane Database of Systematic Reviews 2012, Issue in press.

\section{Moyer 1999}

Moyer CA, Stern DT, Katz SJ, Fendrick AM. "We got mail": electronic communication between physicians and patients. American Journal of Managed Care 1999;5(12):1513-22.

\section{Moyer 2002}

Moyer CA, Stern DT, Dobias KS, Cox DT, Katz SJ. Bridging the electronic divide: patient and provider perspectives on e-mail communication in primary care. American Journal of Managed Care 2002;8(5):427-33.

\section{Neville 2004}

Neville RG, Marsden W, McCowan C, Pagliari C, Mullen $\mathrm{H}$, Fannin A. Email consultations in general practice. Informatics in Primary Care 2004;12(4):207-14.

\section{NHS Connecting for Health 2011}

NHS Connecting for Health. Electronic Prescription Service (EPS). http://www.connectingforhealth.nhs.uk/ systemsandservices/eps 2011.

\section{Patterson 2007}

Patterson V, Swinfen P, Swinfen R, Azzo E, Taha H, Wootton R. Supporting hospital doctors in the Middle East by email telemedicine: something the industrialized world can do to help. Journal of Medical Internet Research 2007;9 (4):e30.

\section{Pew 2005}

Pew Internet. The Pew Internet \& American life project. Generations online. www.pewinternet.org/pdfs/ PIP' Generations` Memo.pdf 2005.

\section{Podichetty 2004}

Podichetty V, Penn D. The progressive roles of electronic medicine: benefits, concerns, and costs. The American Journal of the Medical Sciences 2004;328(2):94-9.

Potts 2002

Potts HW, Wyatt JC. Survey of doctors' experience of patients using the Internet. Medical Internet Research 2002; 4(1):e5.

Ryan 2007

Ryan R, Hill S, Broclain D, Horey D, Oliver S, Prictor M, Cochrane Consumers and Communication Review Group. Study Quality Guide. www.latrobe.edu.au/cochrane/ resources.html (accessed December 2008) 2007.

\section{Stiles 2007}

Stiles RA, Deppen SA, Figaro MK, Gregg WM, Jirjis JN, Rothman RL, et al.Behind-the-scenes of patient-centered care: content analysis of electronic messaging among primary care clinic providers and staff. Medical Care 2007; 45(12):1205-9.

\section{Stutchfield 2007}

Stutchfield BM, Jagilly R, Tulloh BR. Second opinions in remote surgical practice using email and digital photography. ANZ Journal of Surgery 2007;77(11):1009-12.

\section{TechWeb Network 2008}

TechWeb Network 2008. TechWeb Encylopedia. http:// www.techweb.com/encyclopedia 2008.

Thede 2007

Thede LQ. Networking via e-mail. Computers, Information and Nursing 2007;25(5):251-3.

Virji 2006

Virji A, Yarnall KS, Krause KM, Pollak KI, Scannell MA, Gradison $\mathrm{M}$, et al.Use of email in a family practice setting: opportunities and challenges in patient- and physicianinitiated communication. BMC Medicine 2006;4:18. [DOI: $10.1186 / 1741-7015-4-18]$

Vodopivec-Jamsek 2012 in press

Vodopivec-Jamsek V, de Jongh T, Gurol-Urganci I, Atun R Car J. Mobile phone messaging for preventive health care. Cochrane Database of Systematic Reviews 2012, Issue in press.

\section{Voss 1992}

Voss S. How much do doctors know about the notification of infectious diseases?. BMJ 1992;304(6829):755.

\section{References to other published versions of this review}

\author{
Atherton 2009 \\ Atherton H, Car J, Meyer B, Majeed A. Email for clinical \\ communication between healthcare professionals. Cochrane \\ Database of Systematic Reviews 2009, Issue 3. [DOI: \\ 10.1002/14651858.CD007979] \\ * Indicates the major publication for the study
}




\section{CHARACTERISTICS OF STUDIES}

\section{Characteristics of included studies [ordered by study ID]}

\section{Feldstein 2006}

Methods
Study design: Randomised controlled clinical trial.

Duration of follow up study: at 6 months.

Recruitment: Potential patients were identified via health maintenance organisation (HMO) electronic databases
Participants

Interventions
Description and setting: Female patients within a Pacific Northwest HMO were randomised into the study and their physicians received the intervention

Inclusions: Female, aged 50 to 89 , HMO members, no pharmacological treatment, no bone mineral density (BMD) measurements

Exclusions: Having received a pharmacological treatment for osteoporosis $(\mathrm{n}=585)$; having received a BMD measurement $(\mathrm{n}=116)$; and having an exclusionary medical condition ( $\mathrm{n}=193$ ), including malignancies (except non-melanoma skin cancers), chronic renal failure, dementia, organ transplant, and cirrhosis, in the 12 months before the start of the study. Being male $(n=223)$, those without a primary care provider $(n=54)$, participants in osteoporosis clinical trials $(n=52)$, nursing home residents $(n=40)$, those without an address $(n=10)$, and research centre employees $(n=4)$. Some patients had more than one exclusion

Numbers randomised: overall 5311 patients and 5159 corresponding primary care providers were approached.Three hundred and twenty-seven women were randomly assigned to usual care $(n=107)$, electronic medical record (EMR) reminder $(n=107)$, or patient reminder group $(n=113)$. (We report data from the usual care and EMR reminder arms only). There were 159 primary care providers involved in the study

There were two intervention arms: electronic medical record (EMR) and EMR+patient reminder. The latter arm was not included in our review

EMR:

Primary care providers received patient-specific EMR 'in-basket' messages for their enrolled patients from the chairman of the osteoporosis quality-improvement committee. 'In basket' messages are an EMR based email communication used exclusively for patient care activities. The letter-style message informed the provider of the patient's risk of osteoporosis based upon the patient's age and prior fracture and stated the need for evaluation and treatment. At 3 months after the first message, a reminder (specific to individual patients) was sent to primary care providers who had not ordered a BMD or pharmacological osteoporosis treatment for enrolled patients $\mathrm{EMR}+$ patient:

In the EMR + patient reminder arm, primary care physicians received the EMR message and patients received a single mailing of an advisory letter with educational materials addressing menopause, osteoporosis, calcium and vitamin D, physical activity, home safety, and fall prevention. Providers assigned to this study arm received a copy of the letter sent to the patient when the provider received the in-basket reminder. These patients were not included in our review

Control: patients in the usual care arm continued to receive care at the HMO through the normal pathway 
Feldstein 2006 (Continued)

Outcomes

Risk of bias

\begin{tabular}{|c|c|c|}
\hline Bias & Authors' judgement & Support for judgement \\
\hline $\begin{array}{l}\text { Random sequence generation (selection } \\
\text { bias) }\end{array}$ & Low risk & $\begin{array}{l}\text { Generated via a computer random-number } \\
\text { generator seeded by date and time once at } \\
\text { the start of the study }\end{array}$ \\
\hline
\end{tabular}

Allocation concealment (selection bias) High risk

Blinding (performance bias and detection High risk

bias)

All outcomes

Incomplete outcome data (attrition bias) Low risk

All outcomes
Proportion of the study population who received a pharmacological treatment or a BMD

(Pharmacological treatment was defined as any dispensing of a medication for osteoporosis identified electronically from the outpatient pharmacy system)

Regular physical activity and total caloric expenditure

(via the Community Health Activities Model Program for Seniors questionnaire)

Total calcium intake (assessed by questionnaire at baseline and 6 months after the intervention)

Patient satisfaction (assessed by questionnaire at baseline and 6 months after the intervention) measurement within 6 months after the intervention

$\begin{array}{ll} & \text { patients) were blinded to group assignment } \\ \text { However the study analyst assessing the } \\ \text { outcomes was blinded to the treatment } \\ \text { groups }\end{array}$
port and authors stated in contact that allocation was known

Due to the nature of the intervention neither the study nurse conducting the interventions nor the participants (providers or patients) were blinded to group assignment

The response rate to the 6 month questionnaire was $55 \%$. There was an exploration of non-responders. The only significant difference between responders and non-responders was that responders were less likely to have had a clinical vertebral fracture $(P=0.01)$. They were not significantly different to responders with regard to age, Charlson Comorbidity Index score and the percentage who had a hip fracture or wrist fracture as compared with other fractures

Selective reporting (reporting bias) Low risk

There was no published study protocol. There was no evidence of selective reporting in this study; the outcomes presented

Email for clinical communication between healthcare professionals (Review)

Copyright (c) 2012 The Cochrane Collaboration. Published by John Wiley \& Sons, Ltd. 
Feldstein 2006 (Continued)

in the methods section matched those in the results section of the report

Other bias $\quad$ Unclear risk

Baseline comparability: Data are presented comparing the two groups. $\mathrm{Chi}^{2}$ tests between the study arms were all not significant.

Validation of measures: The authors state that primary outcome measure was selected to be consistent with guideline-based care recommendations but no reference is provided. The Community Health Activities Model Program for Seniors questionnaire is referenced. It is not clear how total calcium intake was assessed but two questionnaires are referenced. There was no description or reference for the patient satisfaction questionnaire

Reliability of measures: Several measures are self-reported and this can lead to inaccuracies. Self-reported measures of physical activity and calorie expenditure are prone to reporter bias because of their sensitive nature

\section{Characteristics of excluded studies [ordered by study ID]}

\begin{tabular}{ll}
\hline Study & Reason for exclusion \\
\hline Chen 2010 & Communication was one-way rather than two-way between healthcare professionals \\
\hline Edward 2007 & Communication was one-way rather than two-way between healthcare professionals \\
\hline Feldman 2005 & Communication was one-way rather than two-way between healthcare professionals \\
\hline Jaatinen 2002 & Email component was not assessed separately from the rest of the intervention \\
\hline Johansson 2009 & Communication was one-way rather than two-way between healthcare professionals \\
\hline Lester 2004 & Communication was one-way rather than two-way between healthcare professionals \\
\hline Lester 2006 & Communication was one-way rather than two-way between healthcare professionals \\
\hline
\end{tabular}

Mandall 2005 Communication was one-way rather than two-way between healthcare professionals 
(Continued)

Murtaugh 2005 Same study as Feldman 2005. Feldman 2005 presents patient outcomes, Murtaugh 2005 presents healthcare professional outcomes in the context of nurse education. Studies concerned with email solely for educational purposes are excluded from this review

Persell $2008 \quad$ Email component was not assessed separately from the rest of the intervention

Ward 2008 Multifaceted Internet intervention with an email component. The effects of email are not individually reported. Communication was one-way rather than two-way between healthcare professionals

\section{Characteristics of ongoing studies [ordered by study ID]}

\section{Cline 2007}

\begin{tabular}{ll}
\hline Trial name or title & $\begin{array}{l}\text { Patient specific feedback increases referral of hypertensive emergency department patients: a randomised } \\
\text { controlled trial }\end{array}$ \\
\hline Methods & Randomised controlled trial. \\
\hline Participants & 30 emergency medicine residents. \\
\hline Interventions & $\begin{array}{l}\text { During the } 4 \text { month intervention phase, feedback residents received bi-weekly emails describing completed } \\
\text { or missed referrals of patients who were noted on a weekly chart review to meet hypertension criteria. A total } \\
\text { of } 2,191 \text { hypertensive patient- emergency medicine resident encounters were assessed for refral behaviour }\end{array}$ \\
\hline Outcomes & Baseline referral patterns were observed. \\
\hline Starting date & Unknown. \\
\hline Contact information & dcline@wfubmc.edu \\
\hline Notes & We have contacted the author who explained that the study is completed but has not been written up yet \\
\hline
\end{tabular}

\section{Dalal NCT01153451}

Trial name or title An Automatic Notification System for Test Results Finalized After Discharge

\begin{tabular}{ll}
\hline Methods & RCT (Parallel) \\
\hline
\end{tabular}

Participants

Inclusion Criteria:

- Male or female, 18 years and older.

- Any patient discharged from selected services at BWH whose inpatient attending and primary care provider are in the same arm of the study.

Exclusion Criteria:

- Any patient discharged from selected services at BWH whose inpatient attending and primary care provider are in discordant arms of the study. 


\section{Dalal NCT01153451 (Continued)}

\begin{tabular}{|c|c|}
\hline Interventions & $\begin{array}{l}\text { Email Notification arm: responsible inpatient and ambulatory physicians will receive automated email(s) of } \\
\text { patients' tests results finalized post-discharge generated from the notification system. Finalized results will be } \\
\text { batched such that no provider will receive more than one email per day } \\
\text { Brigham Women's Hospital inpatient clinical information systems will automatically file all non-finalized } \\
\text { chemistry, hematology, pathology, and radiology tests, as well as inpatient and ambulatory provider email } \\
\text { addresses for all study patients discharged. This process will be initiated using a time stamp most proximate } \\
\text { to actual discharge time. At midnight on every day, all tests filed at time of discharge will be updated if final } \\
\text { results have become available. An email with all finalized and pending test results for each patient discharged } \\
\text { will be sent to the inpatient and primary care provider at this time. For patients discharged with more than } \\
\text { one pending test, subsequent email notification(s) will be sent out until all pending tests are finalized (no } \\
\text { more than one email per day) }\end{array}$ \\
\hline Outcomes & $\begin{array}{l}\text { Primary Outcome: } \\
\text { - Awareness of post-discharge test results among responsible inpatient providers ( } 72 \text { hours after } \\
\text { notification). } \\
\text { Secondary Outcomes: } \\
\text { - Awareness of post-discharge test results by responsible outpatient providers (both inside and outside of } \\
\text { Partners at } 72 \text { hours after notification). } \\
\text { - Awareness of actionable test results by responsible providers (at } 72 \text { hours after notification). } \\
\text { - Provider satisfaction with the notification system (at } 72 \text { hours after notification). }\end{array}$ \\
\hline Starting date & July 2010 \\
\hline Contact information & $\begin{array}{l}\text { Anuj K Dalal, MD. Brigham and Women's Hospital, Boston, Massachusetts, United States. } \\
\text { adalal1@partners.org }\end{array}$ \\
\hline Notes & Estimate study completion date December 2011 but as of June 2012 not yet published \\
\hline
\end{tabular}


DATA ANDANALYSES

Comparison 1. Email reminder compared to usual care - Primary outcome: professional actions or performance

\begin{tabular}{|c|c|c|c|c|}
\hline Outcome or subgroup title & $\begin{array}{l}\text { No. of } \\
\text { studies }\end{array}$ & $\begin{array}{c}\text { No. of } \\
\text { participants }\end{array}$ & Statistical method & Effect size \\
\hline $\begin{array}{l}1 \text { Patient rec'd bone mineral } \\
\text { density measurement }\end{array}$ & 1 & 202 & Odds Ratio (M-H, Fixed, 95\% CI) & $31.17[4.13,235.51]$ \\
\hline $\begin{array}{l}2 \text { Patient rec'd BMD measurement } \\
\text { or medication }\end{array}$ & 1 & 202 & Odds Ratio (M-H, Fixed, 95\% CI) & $16.80[6.75,41.85]$ \\
\hline 3 Patient received medication only & 1 & 202 & Odds Ratio (M-H, Fixed, 95\% CI) & $3.27[1.02,10.51]$ \\
\hline $\begin{array}{l}4 \text { Patient received neither BMD } \\
\text { measurement nor medication }\end{array}$ & 1 & 202 & Odds Ratio (M-H, Fixed, 95\% CI) & $0.06[0.02,0.15]$ \\
\hline $\begin{array}{l}5 \text { Absolute change in probability of } \\
\text { receiving BMD measurement }\end{array}$ & & & Other data & No numeric data \\
\hline $\begin{array}{l}6 \text { Absolute change in probability } \\
\text { of receiving osteoporosis } \\
\text { measurement }\end{array}$ & & & Other data & No numeric data \\
\hline $\begin{array}{l}7 \text { Absolute change in probability } \\
\text { of receiving either a BMD } \\
\text { measurement or osteoporosis } \\
\text { medication }\end{array}$ & & & Other data & No numeric data \\
\hline
\end{tabular}

\section{Analysis I.I. Comparison I Email reminder compared to usual care - Primary outcome: professional actions or performance, Outcome I Patient rec'd bone mineral density measurement.}

Review: Email for clinical communication between healthcare professionals

Comparison: I Email reminder compared to usual care - Primary outcome: professional actions or performance

Outcome: I Patient rec'd bone mineral density measurement

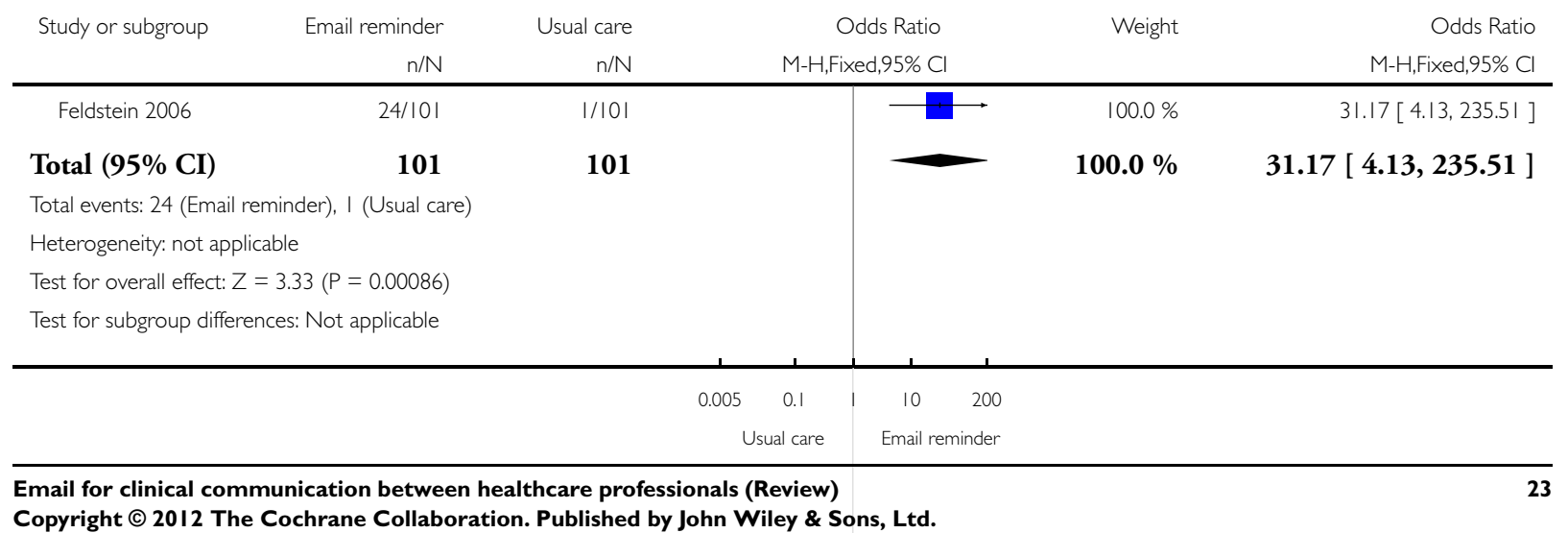


Analysis I.2. Comparison I Email reminder compared to usual care - Primary outcome: professional actions or performance, Outcome 2 Patient rec'd BMD measurement or medication.

Review: Email for clinical communication between healthcare professionals

Comparison: I Email reminder compared to usual care - Primary outcome: professional actions or performance

Outcome: 2 Patient rec'd BMD measurement or medication

\begin{tabular}{|c|c|c|c|c|c|}
\hline \multirow[t]{2}{*}{ Study or subgroup } & \multirow{2}{*}{$\begin{array}{r}\text { Email reminder } \\
\mathrm{n} / \mathrm{N}\end{array}$} & \multirow{2}{*}{$\begin{array}{r}\text { Usual care } \\
\mathrm{n} / \mathrm{N}\end{array}$} & \multirow{2}{*}{ Odds Ratio } & \multirow[t]{2}{*}{ Weight } & \multirow{2}{*}{$\begin{array}{r}\text { Odds Ratio } \\
\text { M-H,Fixed,95\% Cl }\end{array}$} \\
\hline & & & & & \\
\hline Feldstein 2006 & $52 / 101$ & $6 / 101$ & & $100.0 \%$ & $16.80[6.75,41.85]$ \\
\hline Total (95\% CI) & 101 & 101 & $<$ & $100.0 \%$ & $16.80[6.75,41.85]$ \\
\hline \multicolumn{6}{|c|}{ Total events: 52 (Email reminder), 6 (Usual care) } \\
\hline \multicolumn{6}{|c|}{ Heterogeneity: not applicable } \\
\hline \multicolumn{6}{|c|}{ Test for overall effect: $Z=6.06(P<0.0000 I)$} \\
\hline \multicolumn{6}{|c|}{ Test for subgroup differences: Not applicable } \\
\hline
\end{tabular}


Analysis I.3. Comparison I Email reminder compared to usual care - Primary outcome: professional actions or performance, Outcome 3 Patient received medication only.

Review: Email for clinical communication between healthcare professionals

Comparison: I Email reminder compared to usual care - Primary outcome: professional actions or performance

Outcome: 3 Patient received medication only

\begin{tabular}{ccccc} 
Study or subgroup & Email reminder & Usual care & Odds Ratio & Weight \\
& $\mathrm{n} / \mathrm{N}$ & $\mathrm{n} / \mathrm{N}$ & $\mathrm{M}-\mathrm{H}$, Fixed,95\% Cl & $\mathrm{M}-\mathrm{H}, \mathrm{Fixed}, 95 \% \mathrm{Cl}$ \\
\hline Feldstein 2006 & $12 / 101$ & $4 / 101$ & $100.0 \%$
\end{tabular}

Total (95\% CI)

101

101

$100.0 \%$

$3.27[1.02,10.51]$

Total events: 12 (Email reminder), 4 (Usual care)

Heterogeneity: not applicable

Test for overall effect: $Z=1.99(P=0.047)$

Test for subgroup differences: Not applicable

$\begin{array}{lllllll}0.1 & 0.2 & 0.5 & 1 & 2 & 5 & 10\end{array}$

Usual care Email reminder

Analysis I.4. Comparison I Email reminder compared to usual care - Primary outcome: professional actions or performance, Outcome 4 Patient received neither BMD measurement nor medication.

Review: Email for clinical communication between healthcare professionals

Comparison: I Email reminder compared to usual care - Primary outcome: professional actions or performance

Outcome: 4 Patient received neither BMD measurement nor medication

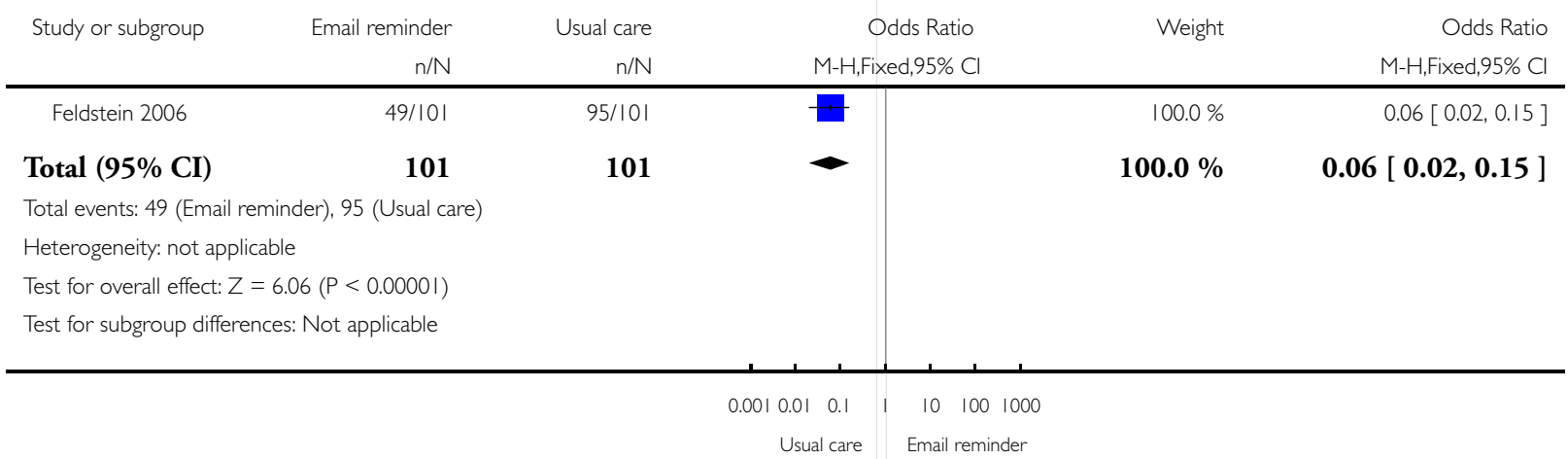


Analysis I.5. Comparison I Email reminder compared to usual care - Primary outcome: professional actions or performance, Outcome 5 Absolute change in probability of receiving BMD measurement.

Absolute change in probability of receiving BMD measurement

Study

Feldstein $2006 \quad 0.39(95 \%$ CI: 0.28-0.50)

Analysis I.6. Comparison I Email reminder compared to usual care - Primary outcome: professional actions or performance, Outcome 6 Absolute change in probability of receiving osteoporosis measurement.

Absolute change in probability of receiving osteoporosis measurement

Study

Feldstein $2006 \quad 0.23$ (95\% CI: 0.12-0.33)

Analysis I.7. Comparison I Email reminder compared to usual care - Primary outcome: professional actions or performance, Outcome 7 Absolute change in probability of receiving either a BMD measurement or osteoporosis medication.

Absolute change in probability of receiving either a BMD measurement or osteoporosis medication

Study

Feldstein $2006 \quad 0.47$ (95\% CI: 0.35-0.59)

\section{A P P E N D I C E S}

\section{Appendix I. Methods for application in future updates}

Outlined here are methods to be applied in any future updates of this review, should studies be identified for inclusion.

\section{Unit of analysis issues}

Issues may arise from the inclusion of cluster-randomised trials, repeated measurements and studies with more than two treatment groups. If applicable the data will be analysed according to recommendations in the Cochrane Collaboration Open Learning Module on issues related to the unit of analysis (Alderson 2002).

\section{Dealing with missing data}

If data are missing from the relevant comparisons we will attempt to contact the authors of the studies to obtain the information. If the authors cannot be reached, or if the studies are found to be unsatisfactory on the basis of data provided, these studies will be excluded. 


\section{Assessment of heterogeneity}

Firstly, heterogeneity will be identified by visual inspection of forest plots. Where confidence intervals for individual studies have poor overlap it generally indicates the presence of statistical heterogeneity.

Secondly, a standard $\mathrm{Chi}^{2}$ test will be used to formally test for the presence of statistical heterogeneity. Where a meta-analysis includes studies with a small sample size or where studies are few in number the $\mathrm{Chi}^{2}$ test has low power. To allow for this a $\mathrm{P}$ value of 0.10 (rather than 0.05 ) will be used to determine statistical significance. Though a significant result may indicate a problem with heterogeneity, a non-significant result does not provide evidence of no heterogeneity.

As well as carrying out a $\mathrm{Chi}^{2}$ test, an $\mathrm{I}^{2}$ statistic will be used. The test assesses the impact of heterogeneity on the meta-analysis, rather than simply testing whether heterogeneity is present. The $\mathrm{I}^{2}$ statistic quantifies inconsistency across the studies. It describes the $\%$ of the variability in effect estimates that is due to heterogeneity rather than sampling error.

The importance of the observed value of $\mathrm{I}^{2}$ depends on the magnitude and direction of effects, and the strength of the evidence for heterogeneity $\left(\mathrm{Chi}^{2}\right.$ test, confidence intervals for $\left.\mathrm{I}^{2}\right)$. Both the $\mathrm{Chi}^{2}$ value and the $\mathrm{I}^{2}$ value can be used together to assess the potential statistical heterogeneity in a meta-analysis.

Where statistical heterogeneity is identified reasons for the heterogeneity will be sought by examining clinical and methodological heterogeneity. These are assessed by comparing the included studies according to participants, interventions, outcomes and study designs, by assessing the risk of bias and by examining subgroups. The level of statistical heterogeneity present will be taken into account when choosing the method of analysis for the review.

\section{Assessment of reporting biases}

Where data in the review have been standardised and pooled, funnel plots will be used to check for publication bias. Funnel plots are produced using Review Manager 5 software.

In interpreting the funnel plot it is necessary to consider possible reasons for asymmetry other than publication bias and these might include poor methodological design and sampling variation.

\section{Data synthesis}

Data synthesis will comprise a narrative overview of the findings. This would be followed by a quantitative meta-analysis if appropriate. The decision to carry out a meta-analysis is dependent on the nature of the studies included in the review. The diversity between studies according to clinical factors, comparisons and outcomes will be considered.

The decision is likely to depend upon the type of intervention and the outcome measures used in the study. Therefore studies should be classified according to:

- Study design: RCTs, CBAs, ITS.

- Outcome measures used, as described under Types of outcome measures

The risk of bias in the included studies will also be considered. Where there is great diversity between studies, and/or a high risk of bias, it is not necessarily appropriate to pool the data. A decision on whether to carry out a meta-analysis will made be according to these factors and after discussion amongst study authors.

Where it is deemed appropriate to carry out a meta-analysis the choice of model will be influenced by the level of statistical heterogeneity identified using both the $\mathrm{Chi}^{2}$ and $\mathrm{I}^{2}$ test.

A random-effects meta-analysis assumes that the studies are not all estimating the same intervention effect. It can be used to incorporate heterogeneity among studies. It is not a substitute for a thorough investigation of heterogeneity and is intended primarily for heterogeneity that cannot be explained. It provides a more conservative estimate of effect. A fixed-effect meta-analysis assumes that each study is estimating exactly the same quantity and that any variation between the results of the studies is due to chance. It more precise than a random-effects model, because in the presence of statistical heterogeneity it usually has narrower confidence intervals.

We will conduct the analysis according to Cochrane Handbook guidance (Higgins 2008).

\section{Subgroup analysis and investigation of heterogeneity}

Where relevant, subgroup analysis will allow the examination of the effect of certain studies on the pooled effects of the intervention. 1. Age

Consideration of the acceptability to different age groups (for both healthcare professionals and patients). This is important as there is clear evidence that the use of email is predicted by age with a clear tailing off in the generation who have not grown up in the

Email for clinical communication between healthcare professionals (Review) 
digital age. It is therefore important to consider the intervention effect in the groups which are accustomed to the technology, since the intervention is likely to become more generalisable to the population as it ages. This will be considered where the primary studies seek to consider age group from the outset. We would have distributed patients into three age subgroups: 0 to 17,18 to 64 , over 65 . The choice of distribution was made on the basis of two surveys by The Pew Internet \& American Life survey (Pew 2005).

\section{Location}

Location of the studies will also be considered, since differing environments may condition the accessibility of the technology. For instance we might expect communication technologies and their accessibility to differ according to country and/or region, or according to whether the study is set in a rural or urban area.

3. Type of email communication

Additionally we propose to analyse the results by method of electronic mail utilized e.g. standard email versus a secure web messaging service where relevant.

4. Year of Publication

Lastly we will consider results by year of publication, as those more recent studies may be more relevant given evidence of increasing usage and therefore assumed acceptability.

\section{Sensitivity analysis}

Studies deemed to be of lower quality after examination of individual study characteristics and assessment of risk of bias will be removed from the analysis to examine the effects of this on the pooled effects of the intervention.

We would exclude studies according to the following filters:

- Outlying studies after initial analysis.

- Largest studies.

- Unpublished studies.

- Language of publication.

- Source of funding (e.g. public versus industry).

Other possible considerations for sensitivity analysis would include different measures of effect size (risk difference, odds ratios).

\section{Appendix 2. MEDLINE (OvidSP) search strategy}

1. computer communication networks/

2. limit 1 to $\mathrm{yr}=$ "1996 - 2002"

3. electronic mail/

4. (electronic mail* or email* or e-mail* ${ }^{*}$ or web mail* or webmail* or internet mail* or mailing list* or discussion list* ${ }^{*}$ listserv*).tw.

5. ((patient or health or information or web or internet) adj portal*).tw.

6. (patient adj (web* or internet)).tw.

7. ((web* or internet or www or electronic* or online) adj5 (messag* or communicat* or transmi* or transfer* or send* or deliver* or feedback or letter* or interactiv* ${ }^{*}$ or input* or forum or appointment* or booking* or remind* or referral* or consult ${ }^{*}$ or prescri*)).tw.

8. ((online or web* or internet) adj4 (service* or intervention* or therap* or treatment* or counsel*)).tw.

9. (e-communication* ${ }^{*}$ or e-consult* or e-visit* or e-referral* ${ }^{*}$ or e-booking* or e-prescri*).tw.

10. or/2-9

11. physician patient relations/

12. professional patient relations/

13. interprofessional relations/

14. remote consultation/

15. or/11-14

16. internet/

17. 15 and 16

18. 10 or 17

19. randomized controlled trial.pt.

20. controlled clinical trial.pt.

21. random*.tw.

22. placebo*.tw.

Email for clinical communication between healthcare professionals (Review)

Copyright $\odot 2012$ The Cochrane Collaboration. Published by John Wiley \& Sons, Ltd. 
23. drug therapy.fs.

24. trial.tw.

25. groups.tw.

26. clinical trial.pt.

27. evaluation studies.pt.

28. research design/

29. follow up studies/

30. prospective studies/

31. (control* or prospectiv* or volunteer*).tw.

32. cross over studies/

33. comparative study.pt.

34. experiment*.tw.

35. time series.tw.

36. (pre test or pretest or post test or posttest).tw.

37. (pre intervention or preintervention or post intervention or postintervention).tw.

38. (impact* or intervention* or chang*).tw.

39. effect?.tw.

40. or/19-39

41. exp animals/ not humans.sh.

42. 40 not 41

43. 18 and 42

\section{Appendix 3. EMBASE (OvidSP) search strategy}

1. e-mail/

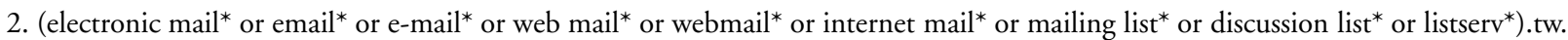

3. ((patient or health or information or web or internet) adj portal*).tw.

4. (patient adj (web* or internet)).tw.

5. ((web* or internet or www or electronic* or online) adj5 (messag* or communicat* or transmi* or transfer* or send* or deliver* or feedback or letter* or interactiv* ${ }^{*}$ or input* ${ }^{*}$ or forum or appointment* or booking* ${ }^{*}$ or scheduling or remind* ${ }^{*}$ or referral ${ }^{*}$ or consult* or $^{*}$ prescri*)).tw.

6. ((online or web* ${ }^{*}$ or internet) adj4 (service* or intervention* ${ }^{*}$ or therap* or treatment* ${ }^{*}$ or counsel*)).tw.

7. (e-communication* ${ }^{*}$ or e-consult* or e-visit* ${ }^{*}$ or e-referral* ${ }^{*}$ or e-booking* or e-prescri* $\left.^{*}\right)$.tw.

8. or/ $1-7$

9. doctor patient relation/

10. interpersonal communication/

11. human relation/

12. patient counseling/

13. exp telemedicine/

14. telecommunication/

15. exp diagnostic test/

16. or/9-15

17. internet/

18. 16 and 17

19. 8 or 18

20. randomized controlled trial/

21. single blind procedure/ or double blind procedure/

22. crossover procedure/

23. random*.tw.

24. trial.tw.

25. placebo*.tw.

Email for clinical communication between healthcare professionals (Review)

Copyright $\odot 2012$ The Cochrane Collaboration. Published by John Wiley \& Sons, Ltd. 
26. ((singl* or doubl*) adj (blind* or mask*)).tw.

27. (experiment* or intervention*).tw.

28. (pre test or pretest or post test or posttest).tw.

29. (preintervention or postintervention).tw.

30. (cross over or crossover or factorial* or latin square).tw.

31. (assign* ${ }^{*}$ or allocat* or volunteer*).tw.

32. (control* or compar* or prospectiv*).tw.

33. (impact* or effect? or chang* or evaluat*).tw.

34. time series.tw.

35. or/20-34

36. nonhuman/

37.35 not 36

38. 19 and 37

\section{Appendix 4. PsycINFO (OvidSP) search strategy}

1. exp electronic communication/

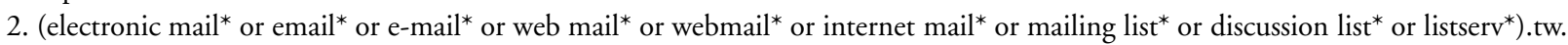

3. ((patient or health or information or web or internet) adj portal*).tw.

4. (patient adj (web* or internet)).tw.

5. ((web* or internet or www or electronic* or online) adj5 (messag* or communicat* or transmi* or transfer* or send* or deliver* or feedback or letter* or interactiv* or input* or forum or appointment* or booking* or schedul* or remind* or referral* or consult ${ }^{*}$ or prescri*)).tw.

6. ((online or web* or internet) adj4 (service* or intervention* or therap* or treatment* or counsel*)).tw.

7. online therapy/

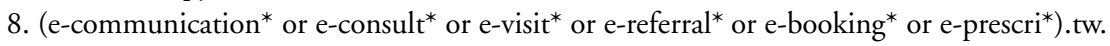

9. or/1-8

10. exp therapeutic processes/

11. interpersonal communication/

12. telemedicine/

13. feedback/

14. or/10-13

15. internet/

16. exp internet usage/

17. 15 or 16

18. 14 and 17

19. 9 or 18

20. (“32" or " 33 ” or " 34 ").cc.

21. (health* or medic* or patient* or clinic* or hospital* or illness* or disease* or disorder* or therap* or physician* or doctor* or psychotherap* or psychiatr* $^{*}$ or telemedic* or treatment* or consult* or counsel* or referral* or remind* or appointment* ${ }^{*}$ or booking* $^{*}$ or schedul* or visit* or prescri* or promot* ${ }^{*}$ or prevent* or diagnos* or test result* or screen* or intervention* or care).ti,ab,hw,id.

22. 20 or 21

23. 19 and 22

24. random*.ti,ab,hw,id.

25. (experiment* or intervention*).ti,ab,hw,id.

26. trial*.ti,ab,hw,id.

27. placebo*.ti,ab,hw,id.

28. groups.ab.

29. ((singl* ${ }^{*}$ or doubl* or trebl* or tripl*) and (blind* or mask*)).ti,ab,hw,id.

30. (pre test or pretest or post test or posttest).ti,ab,hw,id.

31. (preintervention or postintervention).ti,ab,hw,id.

32. (cross over or crossover or factorial* or latin square).ti,ab,hw,id.

Email for clinical communication between healthcare professionals (Review)

Copyright $\odot 2012$ The Cochrane Collaboration. Published by John Wiley \& Sons, Ltd. 
33. (assign* or allocat* or volunteer*).ti,ab,hw,id.

34. (control* or compar* or prospectiv*).ti,ab,hw,id.

35. (impact* or effect? or chang* or evaluat*).ti,ab,hw,id.

36. time series.ti,ab,hw,id.

37. exp experimental design/

38. (“ 0430 ” or “ 0450 ” or " 0451 ” or “ 1800 ” or “ 2000 ”).md.

39. or/24-38

40. limit 39 to human

41.23 and 40

\section{Appendix 5. ERIC (CSA) search strategy}

$\left(\mathrm{KW}=\right.$ (computer mediated communication* ${ }^{*}$ or electronic mail* or email* or e-mail* or web mail* or webmail* or internet mail ${ }^{*}$ or mailing list* or discussion list* or listserv*) or $\mathrm{KW}=\left(\left(\right.\right.$ patient or health or information or web or internet) within 1 portal $\left.{ }^{*}\right)$ or $\mathrm{KW}=$ (patient within 1 (web* or internet)) or $\mathrm{KW}=\left(\left(\right.\right.$ web $^{*}$ or internet or www or electronic* or online or on-line) within 5 (messag* or communicat* or transmi* or transfer* or send* or deliver* or feedback or letter* or interactiv* or input* or forum or appointment* or booking* or schedul* or remind* or referral* or consult* or prescri*)) or KW=((online or on-line or web* or internet) within 4 (service*

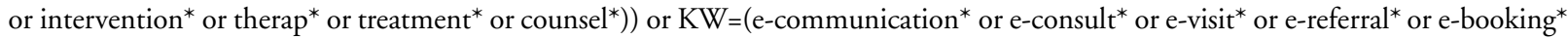
or e-prescri*) $)$ and $\left(\mathrm{KW}=\left(\right.\right.$ health* or medic* or patient* or clinic* ${ }^{*}$ or hospital* or illness* or disease* ${ }^{*}$ or disorder* ${ }^{*}$ or therap* ${ }^{*}$ or physician*

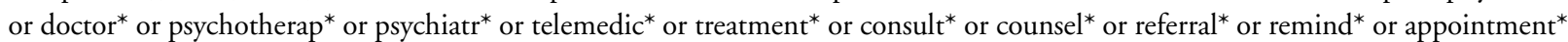
or booking* or schedul* or visit* or prescri* ${ }^{*}$ or promot* or prevent* or diagnos* or test result* or screen* or intervention* or care)) and $\left(\mathrm{KW}=\left(\right.\right.$ random $^{*}$ or trial* ${ }^{*}$ or placebo* ${ }^{*}$ or assign* ${ }^{*}$ or allocat ${ }^{*}$ or volunteer* ${ }^{*}$ or crossover or cross over or factorial* or singl* blind $^{*}$ or doubl* blind* or clinical stud* or longitudinal stud* or control* or compar* or intervention* or preintervention or postintervention or pre test or pretest or post test or posttest or experiment* or prospectiv* or chang* or evaluat* or impact* or effect* or time series))

\section{Appendix 6. CENTRAL search strategy}

\section{\#1 MeSH descriptor Electronic Mail, this term only}

\#2 (electronic-mail* ${ }^{*}$ er email $^{*}$ or e-mail* ${ }^{*}$ or web-mail* ${ }^{*}$ or webmail* or internet-mail* or mailing-list or discussion-list or listserv*):ti,ab,kw

\#3 (patient or health or information or web or internet) next portal

\#4 patient next (web or internet)

\#5 (web* or internet or www or electronic* or online or on-line) near (messag* or communicat* or transmi* or transfer* or send $^{*}$ or deliver* or feedback or letter or interactiv* or input* or forum or appointment or booking or schedul* or remind* or referral or consult* or prescri*)

\#6 (online or on-line or web* or internet) near (service or intervention or therap* or treatment or counsel*)

\#7 e-communication or e-consult* or e-visit or e-referral or e-booking or e-prescri*

\#8 MeSH descriptor Computer Communication Networks, this term only

\#9 (\#8), from 1996 to 2002

Email for clinical communication between healthcare professionals (Review) 


\section{\#10 (\#1 OR \#2 OR \#3 OR \#4 OR \#5 OR \#6 OR \#7 OR \#9)}

\#11 MeSH descriptor Physician-Patient Relations, this term only

\#12 MeSH descriptor Professional-Patient Relations, this term only

\#13 MeSH descriptor Interprofessional Relations, this term only

\#14 “doctor patient relation":kw

\#15 “interpersonal communication”:kw

\#16 "human relation":kw

\#17 “patient counseling”:kw

\#18 MeSH descriptor Telemedicine explode all trees

\#19 telehealth or telemedicine or teleconsultation or telecommunication

\#20 diagnostic-test or laboratory-test

\#21 (\#11 OR \#12 OR \#13 OR \#14 OR \#15 OR \#16 OR \#17 OR \#18 OR \#19 OR \#20)

\#22 internet:kw,ti

\#23 (\#21 AND \#22)

\#24 (\#10 OR \#23)

\#25 (\#24)............... [in Clinical Trials]

\section{Appendix 7. CINAHL (EbscoHOST) search strategy}

Search conducted by Consumers and Communciation Review Group and results sent to us.

\section{H IS T O R Y}

Protocol first published: Issue 3, 2009

Review first published: Issue 9, 2012 


\section{CONTRIBUTIONSOFAUTHORS}

Yannis Pappas carried out data extraction and data analysis and wrote the review.

Helen Atherton wrote the protocol (Atherton 2009), carried out the search, was second data extractor and co-wrote the review.

Prescilla Sawmynaden assisted in the search and was second reviewer.

Josip Car conceived the idea for the review and supervised the production.

\section{DECLARATIONSOF INTEREST}

None known

\section{SOURCES OF SUPPORT}

\section{Internal sources}

- Department of Primary Care and Public Health, Imperial College London, UK.

The review received a partial financial contribution from The Department of Primary Care and Public Health, Imperial College London. The Department of Primary Care \& Public Health at Imperial College is grateful for support from the NIHR Collaboration for Leadership in Applied Health Research \& Care (CLAHRC) Scheme, the NIHR Biomedical Research Centre scheme, and the Imperial Centre for Patient Safety and Service Quality.

- NHS Connecting for Health Evaluation Programme (NHS CFHEP 001), Not specified. http://www.haps.bham.ac.uk/publichealth/cfhep/

\section{External sources}

- Medical Research Council, UK.

HA was the recipient of a Medical Research Council PhD Studentship, administered by Imperial College, London, UK.

\section{DIFFERENCES BETWEEN PROTOCOLANDREVIEW}

We have amended the Background section of the review since the protocol stage (Atherton 2009), to update the cited literature.

\section{Objectives}

Healthcare professional outcomes had been omitted from the objectives despite being one of the outcome categories in the protocol. This category has now been added.

\section{Searches}

We stated in the protocol that the following databases would be searched as part of the grey literature search:

- Dissertation Abstracts (North American and European theses) via British Library

- TrialsCentralTM (www.trialscentral.org)

We did not search the databases, after discussion with the Review Group. TrialsCentral TM was unsearchable; the website seemed only to pull information in from other sources. The only search options were to search by condition or intervention for clinical and drug interventions only (no free text). We did not search Dissertation Abstracts as several of the other databases would duplicate this search (Index to Theses, ProQuest). 


\section{MEDLINE search}

Minor changes were made to the MEDLINE strategy since the protocol stage, in conjunction with the Review Group's Trials Search Coordinator; the latest version is presented at Appendix 2. The changes involved the removal of the term 'on-line' from the strategy. This is because OvidSP MEDLINE changed the way it processed this term, and we were retrieving a very high number of articles $(20,000+)$ whereas before the change in processing we had retrieved around 8000 . Removing this term brought the retrieval rate back to acceptable levels.

\section{Data synthesis}

This section has been amended to accommodate the inclusion of a single study in the review.

\section{INDEX TERMS}

\section{Medical Subject Headings (MeSH)}

*Electronic Mail; ${ }^{*}$ Health Personnel; ${ }^{*}$ Interprofessional Relations; ${ }^{*}$ Osteoporosis [diagnosis; therapy]; ${ }^{*}$ Reminder Systems; Randomized Controlled Trials as Topic

\section{MeSH check words}

Humans 